CONF-801098-23

LBL-12175

\title{
REINJECTION STUDIES OF VAPOR-DOMINATED SYSTEMS
}

Ronald C. Schroeder, Michael J. O'Sullivan, Karsten Pruess, Romano Celati", and Claudio Ruffilli"

\author{
Lawrence Berkeley Laboratory \\ University of California \\ Berkeley, CA 94720
}

October 1980

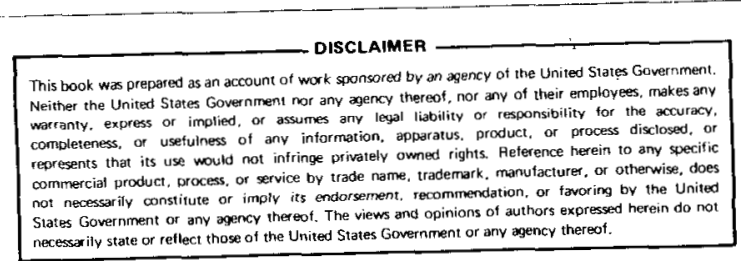

This work was supported by the Assistant Secretary for Resource Applications, Office of Industrial and Utility Applications and Operations, Geothermal Energy Division of the U.S. Department of Energy under Contract No. W-7405-ENG-48.

*Presently at Berkeley Group Inc. \#CNR and ENEL, Pisa, Italy 


\section{DISCLAIMER}

This report was prepared as an account of work sponsored by an agency of the United States Government. Neither the United States Government nor any agency Thereof, nor any of their employees, makes any warranty, express or implied, or assumes any legal liability or responsibility for the accuracy, completeness, or usefulness of any information, apparatus, product, or process disclosed, or represents that its use would not infringe privately owned rights. Reference herein to any specific commercial product, process, or service by trade name, trademark, manufacturer, or otherwise does not necessarily constitute or imply its endorsement, recommendation, or favoring by the United States Government or any agency thereof. The views and opinions of authors expressed herein do not necessarily state or reflect those of the United States Government or any agency thereof. 


\section{DISCLAIMER}

Portions of this document may be illegible in electronic image products. Images are produced from the best available original document. 
REINJECTION STUDIES OF VAPOR-DOMINATED SYSTEMS

by

Ronald C. Schroeder, Berkeley Group Inc. Michael J. O'Sullivan, Lawrence Berkeley Laboratory

Karsten Pruess, Lawrence Berkeley Laboratory

Romano Celati, CNR, Pisa, Italy

Claudio Ruffilli, ENEL, Pisa, Italy

\section{Introduction}

Reinjection of spent geothermal fluids is becoming a common means of waste disposal. In general, injection of geothermal brine has been accomplished without major problems whenever the fluid is injected into large fractures. Descriptions of long-term injection have been made in numerous reports. Chasteen ${ }^{1}$ describes the injection at the Geysers field and at Valles Caldera (Baca). Since 1969, millions of tons of condensate have been injected at the Geysers, and during long-term tests at Baca thousands of tons of produced geothermal fluids have been reinjected. Cuellar ${ }^{2}$, Einarsson et $\mathrm{al}^{3}$, and Witherspoon ${ }^{4}$ reported injection of fluids at Ahuachapan, El Salvador, where over seven thousand tons of spent fluid have been injected since 1970 . Kubota and Aosaki ${ }^{5}$ describe reinjection of spent fluids at Otake, Japan. More than eight million tons had been injected by 1975. Smaller scale disposal of produced brine, or spent condensate has taken place in Hilo, Hawaii; Lardere1lo, Italy; and at the Salton Sea, California ${ }^{6}$. In all of these examples the large-scale injection took place in existing fractures.

When reinjection has been attempted into geological formations that do not have large fractures, the brine disposal has been less successful. At East Mesa considerable problems were encountered, particularly during initial attempts ${ }^{7}$. On the other hand, enormous amounts of brine have been injected into porous aquifers and reservoirs around the world. In the Gulf States, 
water that is produced from gas and oil wells is disposed of in relatively shallow aquifers ${ }^{8}$. In numerous cases around the world, oil is recovered using the secondary recovery method of waterflooding ${ }^{9}$. In a single example10, 4.2 million barrels per day of sea water were injected in a water-flood project in Saudi Arabia. Numerous tertiary steam flooding projects are underway to recover high viscosity crude. Some projects are reclaiming the brine that is produced during oil production, and in one project up to 80 thous and tons per day of brine has been recovered, vaporized, and injected.

Although injection of fluids has been a common practice in both the oil and gas industry, and in the disposal of industrial waste water, the geothermal experience is not as extensive. Temperature effects must be considered in geothermal injection which are not usually important in oil and industrial applications (except steam flooding). Not only are there brine chemistry problems, such as silica deposition, but also significant reservoir problems, such as cold water break-through, which must be resolved prior to geothermal injection.

One of the objectives of task $3 / 6$ was to study the problems encountered and experience required in different geothermal fields.

The data on reinjection in vapor-dominated systems mainly come from Larderello. Reinjection is of utmost inportance in this field because of the decrease in production detected in various productive areas as a consequence of more than 50 years of exploitation. Studies of this field are also of interest as it is considered the only example of an "ageing" steam field, where the problem of maintaining production becomes particularly critical. Reinjection is considered as a means of extracting heat from the geothermal reservoir.

Reinjection has been carried out in peripheral aquifers on the southern margin of the field (Lago, Monterotondo) since 1974, injecting small flow 
rates $\left(30-80 \mathrm{~m}^{3} / \mathrm{h}\right)$. No variation was noted in the trend of production rates and fluid characteristics of the wells nearest the injection points. The small quantities of injected water are believed to mix with much larger volumes of cold water flowing toward the steam field. Systematic injection tests over long periods on the inside of the productive areas began only recently; however, several short tests have been run in the past, and occasionally more than $100 \mathrm{~m}^{3} / \mathrm{h}$ of water was injected into the reservoir over several months, during drilling operations in the deepest wells. In some cases production was very accurately monitored in the surrounding zone.

The most important points originating from these tests are:

- noteworthy increases in steam production were recorded in the wells nearest the injection wel1, when injection took place in the upper layers of the reservoir;

- there were no noticeable effects on the quantity and characteristics of the fluid produced when injection took place at depth. The depth limits for this change vary from zone to zone and are not always easy to define; the different injection depths can only be identified when using completed wells of varying depths in the same area or when inserting, the casings during drilling operations.

Another characteristic of the Larderello field which is important in connection with the reinjection problem is that large volumes of reservoir seem to contain superheated steam only in the pore volume.

Injection phenomena have been studied theoretically for several years, and most of the basic phenomena are now quite we11 understood. Numerous theoretical and numerical studies have been made of both fracture flow and production/injection behavior of porous aquifers. Bodvarsson 11,12, Gringarten et $\mathrm{l}^{13}$, Kasameyer and Schroeder ${ }^{14}$, and Bodvarsson and Tsang ${ }^{15}$ have all examined the temperature behavior of flow through fractures. Gringarten and 
Saut $\mathrm{y}^{16}$, Kasameyer ${ }^{17}$, Tsang and Tsang ${ }^{18}$, Lippmann et al ${ }^{19}$, and numerous others have studied different aspects of production and injection in porous reservoirs.

Although the basic injection phenomena are known, there are many technical and economic problems still remaining that the geothermal engineer must contend with, in particular for aquifers that are not fracture dominated. For example, the amount of particulates can be a crucial factor in the cost of injection when fractures are not present, as they tend to clog the formation and their removal through the use of sand separators, special well completions, and in-line filtering is expensive. Also the brine utilization scheme can have an important effect on the injection system, since a system that results in oxygenation of the fluid to be injected can result in serious corrosion problems. The necessary treatment to prevent excessive corrosion will again have an important impact on cost.

There are significant environmental factors associated with the injection of fluids, and in a previous session of this meeting some of these factors were discussed. Induced seismicity, control of subidence, geochemical brine incompatibility, chemical treatment methods, and the environmental pollution of groundwater (in the case of shallow aquifer injection) are all questions --although site specific--that require additional study before a ful1-scale injection project begins.

The problems of injection well testing, particularly in the case of a boiling reservoir fluid or fracture flow, are numerous and mostly unresolved. Recent studies 20,21 have defined some of the important phenomena.

In addition to the problems associated with the brine chemistry, the reservoir environment, and well testing, there are also significant field management problems. These problems are related to the optimization in the utilization of the resource. The number of wells, the well patterns, the 
amount of fluid injected, and the temperature of the injected fluid must all be chosen to provide a minimum cost for pipelines, pumps, and wells. At the same time, the reservoir pressure (and vapor saturation for two-phase systems), and heat that is captured from the rocks must be maximized by the injection without premature cool-water breakthrough. The "sweep" of heat from the rocks by fluid injection, and the large potential gain in power production that can be realized has been reported by Gringarten and Sauty ${ }^{16}$, Nathenson 21 , Kasameyer and Schroeder ${ }^{14}$, for example.

The availability of large-scale multidimensional and multiphase numerical reservoir simulators now makes it possible to study the reservoir flow phenomena, well test behavior, field management problems, and some of the environmental problems associated with injection. Recent reports by Mangold, et a1 22 , Pritchett, et al $23,0^{\prime}$ Sullivan and Pruess ${ }^{20}$, and others have shown that the application of numerical simulation to geothermal injection is a very fruitful approach.

The purpose of the present work is to review the basic physical phenomena associated with geothermal injection, to discuss problems associated with its numerical simulation and to present the results of some numerical studies. The particular problems chosen for study are:

(1) injection of cold water into a thin (single layer) reservoir;

(2) a five-spot production/injection configuration in a thin (single layer) reservoir;

(3) injection of cold water into a thick (multi-layer) reservoir;

(4) injection of cold water into a one-dimensional vertical column, representing a cross section of Larderello geothermal reservoir.

These four problems by no means include all those of interest and in each case only one set of reservoir parameters is considered. However, they 
provide a means of assessing the accuracy of simulators such as SHAFT 7924 in solving injection problems and in quantitatively discussing the most important physical phenomena which occur.

\section{Injection Physics}

In this section the physics of the flow during injection of fluids is reviewed in two parts. The first part deals with injection into a reservoir that can be approximated as a uniform porous medium for which Darcy's Law is a good approximation, and the second part deals with flow in a reservoir which is dominated by one or more large fractures. The difference between flow in a porous matrix and a fractured matrix is important for both thermal and hydrodynamic phenomena. In a porous material, the temperature of the fluid in the pores is always close to the temperature of the porous matrix. This is not necessarily the case in fractured media. In homogeneous porous media the hydrodynamic flow is slow and often approximately isotropic. In fractured rock, the flow can reach turbulent velocities in the fractures and, in general, fracture flow is not isotropic.

\subsection{Porous Matrix}

When a fluid of temperature $\mathrm{T}_{1}$ is injected into a porous rock formation of temperature $\mathrm{T}_{2}$, two fronts begin to move away from the injection point. The two fronts, shown in Figure 1, are the hydrodynamic front, which occurs at the farthest distance traveled by injected fluid, and the thermal front where temperatures jump from $T_{1}$ to $T_{2}$.

Bodvarsson 12 solved this problem for linear one-phase flow very elegantly, and several others have done so for radial flow.

Kasameyer ${ }^{17}$ showed that in a liquid saturated reservoir a particle of the injected liquid remains at temperature $T_{1}$ for an interval of time given by 


$$
\Delta t_{T_{1}}=\frac{\tau}{1-\tau} t_{p}
$$

where $t_{p}$ is the time (after the injection began) that the particle was injected and $\tau$ is the ratio of "thermal masses" given by

$$
\tau=\frac{\phi \rho_{f} C_{f}}{\phi \rho_{f} C_{f}+(1-\phi) \rho_{r} C_{r}}
$$

Here $\phi$ is porosity, $\rho$ is density, and $C$ is the specific heat capacity. The subscripts $f$ and $r$ refer to fluid and rock, respectively. For typical porous media,

$$
\Delta \mathrm{t}_{1} \approx 0.25 \mathrm{t}_{\mathrm{P}}
$$

This result is applicable if the injected liquid moves with a sharp front (piston displacement). The ratio, $\tau$, can also be shown to give the ratio of the injected volumes behind the thermal and hydrodynamic fronts respectively, that is

$$
\frac{\mathrm{V}_{\mathrm{T}_{1}}}{\mathrm{~V}_{\text {hydro }}}=\tau
$$

When cool liquid is injected into a porous rock that is fully saturated with a two-phase fluid having steam saturation $s_{1}$, the hydrodynamic front can be rather broad. The injected fluid causes steam compression, condensation, and pressure increase in the two-phase zone, giving rise to outward flow of mobile water outside of the swept volume.

In a particular problem studied by $0^{\prime}$ Sullivan and Pruess 20 , the thickness of the zone where liquid water saturation changes from 1 to the undisturbed value of .8 turned out to be about half an order of magnitude in the similarity variable $t / R^{2}$. A formula analogous to (3) above for injection into a twophase reservoir is derived in the appendix. 
The viscosity of fluids--including water--is strongly dependent upon temperature. This results in several important phenomena when the injection temperature, $T_{1}$, differs significantly from the temperature of the country rock, $\mathrm{T}_{2}$. Tsang 18,25 has made several numerical studies of the effects of injection, and Lippmann et al 19 used reservoir simulation to study singlephase viscosity effects. O'Sullivan and Pruess 20 have obtained similar results for a two-phase example. The results obtained by Tsang and Lippmann show that at early times during injection of cold water the pressure response at the injection well is determined by the viscosity of the reservoir fluid at temperature $T_{2}$. The response then quickly undergoes a transition to a steeper growth rate determined by the much higher viscosity of the cold injected fluid. Recent results for the two-phase case are reported below.

In addition to the viscosity effects there are also effects due to the different fluid densities at temperatures $T_{1}$ and $T_{2}$. In the discussion above we have assumed that the flow is radial away from the injection well, and uniform with depth in the reservoir. The effect of different densities of the fluids with temperatures $T_{1}$ and $T_{2}$ is to have the heavier fluid gravitate to the bottom of the reservoir. During injection this results in a front that becomes more and more inclined. As shown in Figure 2, injection of cool fluid in a thick reservoir results in a thermal front which moves faster at the bottom of the reservoir. Nathenson 21 approximated the case of cold water injected into a hot liquid-saturated reservoir. Lippmann 19 , and $\mathrm{Tsang}^{22}$ and coworkers have conducted several numerical studies of injection including the gravity segregation effects.

The effects of gravity segregation when cool liquid is injected into a two-phase reservoir are even more important due to the larger difference in density of the liquid and steam. These effects have also been investigated numerically for two-phase reservoirs and will be covered in detail below. 
The effects of the thermal conductivity of rocks and water have been a subject of study by numerous modelers. The consensus opinion is that the conductivity of the rock is so low--even when fully saturated with liquid-that in most cases the broadening of the thermal front due to heat flow in front of the invading cold water can be neglected. That does not mean that thermal conductivity does not play an important role in geothermal processes, however. The heat losses over large boundaries--particularly from a thin aquifer (reservoir)--can be appreciable. The vertical temperature profile near the ground surface in a very thick geothermal reservoir is governed by conduction effects. We will not discuss this special consideration further.

There are two additional physical phenomena that play an important part in the development of hydrodynamic and thermal fronts. One is the "fingering" effect that develops when the invading fluid and in situ fluid are miscible 26 . In the case of a cool brine invading hot brine, this consideration has importance only with respect to the fluid chemistry of the liquids. This is due to the fact that the mixing occurs at the hydrodynamic front, and hence has only chemical not thermal significance.

However, in the case of liquid injection into a two-phase fluid the miscibility and phase interaction of water and steam might result in considerable broadening of the boiling zone ahead of the hydrodynamic front. In Figure 3 we show an example of fingering taken from Blackwe11, et al26.

Although the fluids in this example are not water and steam, the phenomenon is common to any miscible fluids and becomes more significant as the densities and relative permeabilities of the two miscible fluids become increasingly different (e.g., water and dry steam). The fact that water and steam are interacting phases obviously complicates the analysis of this effect. 
The second consideration, with regard to frontal advance, is hydrodynamic dispersion which applies to both the thermal and hydrodynamic fronts. For the advance of a liquid into a two-phase fluid, the well-known phenomenon of hydrodynamic dispersion 27 might play a significant secondary role in the spreading of the moving two-phase zone ahead of the hydrodynamic front. Hydrodynamic dispersion results in a spreading of the thermal front also (usually referred to as thermal dispersion ${ }^{28}$ ). Considerable effort has been spent in studying dispersion of species concentration ${ }^{29}$. But much less has been accomplished in modeling or analysis of thermal dispersion. Hydrodynamic dispersion of a liquid/two-phase interaction is a totally new consideration and to our knowledge has not been investigated.

\subsection{Fractured Matrix}

Some of the effects discussed above are applicable for injection into fractures. However, there are a number of special considerations that are peculiar to hydrothermal flow in fractures. The most important fracture phenomenon is the anisotropy of the flow that is related to fracture orientation. It should be noted that the presence of fractures does not necessitate modeling the detailed anisotropic flow. Warren and Root 30 , Kasameyer and Schroeder ${ }^{14}$, and others have investigated the fluid and heat flow in distributed fractures. They have shown that there is a range of fracture spacing and aperture over which the rock behaves like a porous anisotropic medium. In this range the fracture orientation is irrelevant. Outside that range of fracture spacing and aperture the fractures must be modeled, taking into account both their orientation and hydrothermal response. For example, the numerical results for plane, parallel fractures indicate that for typical geothermal rocks the fractures can be very widely spaced, $>50 \mathrm{~m}$ say, while still displaying the thermal behavior of an equivalent 
porous medium. The material parameters--porosity and permeability--for the equivalent porous rock are very difficult to estimate or verify, which reduces the practical value of these observations. If the average fracture spacing and aperture can be estimated from drilling, coring, and testing, then the appropriate modeling approach can be chosen.

When the fractures must be modeled as discrete channels, both the fluid flow and heat flow from the rock to the fluid must be modeled accurately. The fluid flow in parallel smooth planar channels was shown to follow the relationship

$$
Q=2 \pi\left[\frac{w^{2}}{12} \frac{w}{\mu}\right] \frac{\Delta p}{\ln r^{r} / r_{w}}
$$

for radial flow. Witherspoon et al 31 have shown that this relationship holds for rough, irregular fractures even for different effective applied stresses across the fracture faces. Here $w$ is the fracture aperture, $\mu$ is viscosity, $P$ is pressure, $r$ is radius, and $Q$ is flow rate. The subscripts $e$ and $w$ refer to a reference radius and to the wellbore radius, respectively. This result suggests that a "fracture permeability" should be defined to be $w^{2} / 12$. Equation (4) holds only for relatively impermeable rock. If the rock has some matrix permeability and "leaks" fluid into the fracture, equation (4) no longer holds true.

The heat flow from the rock to the fluid moving between plane parallel plates has been approximated in studies of the heat transfer properties of geothermal fractures by numerous investigators. The important observation is that a hydrodynamic and thermal front will not move out radially from an injection well when flow is predominantly through fractures. Bodvarsson and Tsang 32 have begun numerical studies of these phenomena for both liquid flow and twophase flow. When flow is through vertical fractures the gravitational effects will be important while the effects of miscibility and dispersion are not. 


\section{Numerical Simulation of Injection}

\section{1 "Front-Dominated" Problems}

From the point of view of numerical modeling, the problem of the injection of cold water into two-phase or steam zones is dominated by the movement of fronts (see Figure 1). As discussed in section 2, there is a hydrodynamic front, which separates the more distant parts of the reservoir from those swept by the injected water, and trailing behind this is a thermal front where the injected fluid makes a transition from reservoir temperature to injection temperature. It is near these fronts where the significant changes occur. The methods of spatial discretization and volume averaging, which are employed in numerical simulators, have inherent limitations for front-dominated problems. The shortcomings of these methods are now discussed in some detail. Subsequently it is shown, by way of numerical experiments as well as analytical methods, that simulation nonetheless yields satisfactory results if executed carefully.

For one-dimensional radial injection into a two-phase reservoir the situation is characterized at all times by a cold zone around the injection we11, surrounded by a swept zone close to original reservoir temperature. Outside of this swept zone, some condensation takes place which is accompanied by slight temperature and pressure increases and outward flow. The basic flaw of finite-discretization modeling of this process is caused by the fact that for some period of time the separation between hydrodynamic and thermal fronts is less than the grid spacing. Therefore, the hydrodynamic front is modeled as having a lower temperature. This causes a spurious flow from the outer zone inward, toward the hydrodynamic front. Actually, the flow induced by cold water injection into a two-phase system is outward, away from the injection well at all times (see below).

In mathematical terms, the difficulties arise from the fact that the applicable mass-and-energy-transport equations are usually predominantly 
diffusive (parabolic) in nature, but display strongly convective (hyperbolic) character in the vicinity of the fronts. It is well known that hyperbolic equations, when solved on a discrete spatial mesh, are subject to much stronger numerical dispersion.

\subsection{Radial Flow}

The simplest and most basic injection problem involves one-dimensional radial flow in a thin reservoir. We have used various grid spacings to simulate the problem defined in Table $1 .(\Delta R=0.5 \mathrm{~m}, 1 \mathrm{~m}, 2 \mathrm{~m}, 4 \mathrm{~m}$. Figures 4 and 5 compare simulated results with semi-analytical solutions obtained from the similarity solution method (reference 20). There is very good agreement for vapor saturations and pressures. The numerical simulation does less well for the temperature front, which is predicted in the proper location, but has been smeared out considerably. The grid spacing used in these simulations is $\Delta \mathrm{R}=1 \mathrm{~m}$. Figure 6 shows that a significant improvement is obtained for a grid spacing of $.5 \mathrm{~m}$.

The satisfactory agreement of the numerical simulation with the similarity-solution method shows that, in spite of the problems noted above, the simulation seems to "work." We shall now examine the numerical simulation in some more detail, in order to develop a better understanding of the operating mechanisms.

After injection starts, the temperature and pressure in the well block decline due to mixing with colder water. This causes a (spurious) flow inward in the reservoir, towards the well block. (Note that water is mobile at initial vapor saturation of $20 \%$ ) After a while a phase transition occurs in the well block. Further injection causes pressure to increase rapidly, and water begins to flow outward into the second grid block. This water has a temperature intermediate between the injection temperature and the original reservoir temperature. The second grid block experiences a sequence 
of events similar to the first grid block: the water inflow from the well block occurs at somewhat lower temperature, causing temperature and pressure in the second grid block to drop and inducing inward flow from the third grid block. Flow reverses after the second grid block makes a phase transition to liquid conditions, and the process continues in the third grid block. Due to repeated contact with the rock and mixing with fluid of original reservoir temperature, the temperature of the hydrodynamic front increases as it moves on from grid block to grid block. The amplitude of the spurious inward flow diminishes in the process, until it finally disappears entirely. The advancing hydrodynamic front causes some steam to compress and condense, thus increasing temperatures slightly above original reservoir temperature. In the simulation, we observe that the hydrodynamic front at late times experiences a temperature increase of $\Delta T=.374^{\circ} \mathrm{C}$. Assuming complete condensation of the steam present in the swept volume a simple heat balance calculation gives a temperature increase of $\Delta \mathrm{T}=.381^{\circ} \mathrm{C}$, in very good agreement with the simulated value. We believe that the outward flow (mostly water) caused by the condensation process is responsible for the very diffuse hydrodynamic front seen in the simulation. Comparison with the similarity solution, Figure 4 , shows that this represents a "real" effect, not an artifact of the simulation. Because the hydrodynamic front is so diffuse, good results can be obtained, even for a large grid spacing of $\Delta R=4 \mathrm{~m}$. The temperature front on the other hand is very sharp, and subject to much stronger numerical dispersion (see Figure 5). For completeness, we mention that a rather sharp hydrodynamic front will occur in the case where there is no mobile liquid water in the reservoir.

Further insight into the simulation can be obtained from a consideration of $t / R^{2}$ invariance. Consider a grid with spacing $\Delta R_{i}$.' It is easy to see from the discretized mass- and energy-transport equations that the entire simulation calculation for radial geometry is invariant under the transformation: 


$$
\begin{aligned}
& \Delta R_{i} \rightarrow \Delta R_{i}^{\prime}=\varepsilon \Delta R_{i} \\
& \Delta t_{k} \rightarrow \Delta t_{k}^{\prime}=\varepsilon^{2} \Delta t_{k}
\end{aligned}
$$

If all radii in the grid are scaled by a factor $\varepsilon$, and all time steps are scaled by a factor $\varepsilon^{2}$, the numerical simulation produces identical results, element for element and time step for time step. The reason for this is that in the finite difference equations time steps and volumes appear only in the combination $\Delta t / V_{i}$, and that the flow terms contain geometrical factors in the form $A_{i j} /\left(d_{i}+d_{j}\right)$. Here $A_{i j}$ is the interface area between grid blocks $i$ and $j$, and $d_{i}$ and $d_{j}$ are the respective distances of the nodal points from the interface. Whereas the solution to the differential equations is strictly dependent upon $t / R^{2}$, the solution of the difference equations has this property only approximately. At different mesh points the solutions at times chosen to give the same $t / R^{2}$ value are not identical because of the time dependence of numerical dispersion. However, as explained above, simultaneous scaling of both the time steps and the grid produces a "discrete" $t / R^{2}$ invariance.

We have verified the above mentioned invariance properties of the difference equations explicitly by means of numerical simulation. Simulated results at $t=160,000 \mathrm{sec}$ for a grid with spacing $\Delta R=4 \mathrm{~m}$ are identical, element for element, with results at $t=40,000 \mathrm{sec}$ for a grid with spacing $\Delta R=2 \mathrm{~m}$. This property was then used to obtain simulations for the finer grids, in the following way. Simulated results at $t=160,000 \mathrm{sec}$ for a grid with $\Delta \mathrm{R}=2 \mathrm{~m}$ were used to initialize the simulation with the $\Delta \mathrm{R}=1 \mathrm{~m}$ grid at $t=40,000 \mathrm{sec}$, and similarly for the $\Delta R=.5 \mathrm{~m}$ grid.

The appendix presents a simple lumped model for computing the movement of hydrodynamic and thermal fronts. From Equations (A.4, A.3) we compute, for $t=1.6 \times 10^{5} \mathrm{sec}$, a radius of the swept zone, $R_{h}=28.31 \mathrm{~m}$. At this 
radius, simulated steam saturation is $11.3 \%$ (see Figure 6 ), which is close to the mean of $0 \%$ and $20 \%$. The slight deviation occurs because the hydrodynamic front is spread out in an asymmetric way, with the inner part being steeper than the outer part. The spreading is a "true" physical phenomenon, not included in our lumped model, which is caused by water flowing outward outside of the swept volume, as a consequence of condensation-induced pressure increase. From Equation (A.4) the lumped model predicts a radius of the cold zone, $\mathrm{R}_{\mathrm{cold}}=6.14 \mathrm{~m}$. At this radius, simulated temperature is $167{ }^{\circ} \mathrm{C}(\Delta \mathrm{R}=0.5 \mathrm{~m} \mathrm{grid})$, which is the exact mean between injection temperature and original reservoir temperature.

In summary we conclude that comparisons with the similarity solution method and use of various grid spacings demonstrate that numerical simulation of injection can produce accurate results. Further insight into the workings and applicability of numerical simulation for injection problems is obtained from a lumped parameter approximation, and from the invariance properties of the governing equations in finite difference form.

\section{Analysis of Injection Well tests}

The results given in Figures $4-7$ apply to a simple constant rate injection test. The semilog plot of the pressure build-up curve shows two straight line sections (Figure 7). The first corresponds to movement of hot water and the second to the movement of cold water. In either case, the mobility of the water can easily be calculated. This is not generally possible for production tests in two-phase reservoirs since the mobility changes during the course of the test and depends in a non-obvious way on the relative permeabilities.

From the straight 1 ine portions of the pressure plot the kinematic mobilities can be calculated from the formulas given by $\operatorname{Garg}^{33}$ as 
$8.23 \times 10^{-7} \mathrm{~s}$ for the $100{ }^{\circ} \mathrm{C}$ water and $1.79 \times 10^{-6} \mathrm{~s}$ for the $234{ }^{\circ} \mathrm{C}$ water. These values compare very well with the exact values of $8.24 \times 10^{-7} \mathrm{~s}$ and $1.73 \times 10^{-6} \mathrm{~s}$ respectively. It is worth mentioning that the wellblock pressure, if referred to a radius of $.56 \mathrm{R}_{\mathrm{w}}\left(\mathrm{R}_{\mathrm{w}}=\right.$ well block radius) as suggested by Garg, yields a point on Figure 7 which is within line thickness of the "cold" straight line.

It is shown in the appendix that the location of the thermal front can be used to estimate porosity. Inserting $R_{c}=6.14 \mathrm{~m}$ for $t=1.6 \times 10^{5} \mathrm{sec}$ (corresponding to $t / R_{c}{ }^{2}=4244.1 \mathrm{~s} / \mathrm{m}^{2}$ ), as read off from Figure 6 into Equation (A.7), yields a very accurate value of $\phi=15.05 \%$. However, taking $t / R_{C}{ }^{2}$ from Figure 7 at the intersection of the two straight lines, $t / R_{c}^{2}=4600 \mathrm{~s} / \mathrm{m}^{2}$, gives $\phi=24.5 \%$. Small inaccuracies in $t / R_{c}{ }^{2}$ translate into large inaccuracies for $\phi$, because in the numerator of Equation (A.7) two large numbers of equal order of magnitude are being subtracted. Field application of this method of porosity estimation has to use the intersection of the two straight lines, and one can not expect very accurate results from this approach.

The excellent agreement between the semi-analytic results and the SHAFT79 results gives confidence in the ability of the simulator, with careful mesh design, to analyse more complicated injection tests including inhomogeneities in the reservoir (skin), constant pressure boundaries (fractures), and variable injection rates.

\section{Five-spot Results}

In order to investigate the optimal use of reinjection in a vapordominated geothermal reservoir, a five-spot configuration of production and injection wells (see Figure 8) was studied. A production well spacing of $1000 \mathrm{~m}$ was assumed and reservoir parameters typical of the Italian reservoirs 
were used (see table 1). The production rate of $0.025 \mathrm{~kg} / \mathrm{sec}$ was chosen to give a supply of fluid in the reservoir sufficient to sustain approximately thirty years of production.

Because of the symmetry of the configuration only one eighth of a typical five-spot has to be considered. The mesh used in the SHAFT79 calculations is shown in Figure 8 . Three cases were considered:

(i) no injection,

(ii) an injection rate equal to the production rate,

(iii) an injection rate double the production rate.

The vapor saturation in the reservoir is sufficiently high so that water is immobile and therefore vigorous boiling is required to maintain the required production rate from steam alone. Therefore the pressure must decline as a consequence of boiling. The permeability in the reservoir is sufficiently high to allow comparatively rapid spreading of boiling and the associated pressure decline. As can be seen in Figure 9, the pressure drops almost uniformly across the reservoir as time progresses, with a corresponding near uniform temperature drop and vapor saturation increase. Once the reservoir has completely superheated (dried out) the amount of mass left in the' reșervoir is very small and the pressure declines very rapidly (see Figure 10). At this stage the reservoir temperature is still high $\left(\approx 220^{\circ} \mathrm{C}\right)$, that is, plenty of heat remains in place. In its unexploited state the reservoir contains $57.4 \times 10^{13} \mathrm{~J}$ of energy of which only $3 \times 10^{13} \mathrm{~J}$ are contained in the fluid. Clearly not all of this energy is available for exploitation. There is a lower limit to the temperature of the reservoir at which production is likely to be useful. For reference, a simple calculation gives the energy contained in the rock matrix at $180^{\circ} \mathrm{C}$ as $39.8 \times 10^{13} \mathrm{~J}$. At the end of its useful life the reservoir still contains $50.0 \times 10^{13} \mathrm{~J}$. Some $4.4 \times 10^{13} \mathrm{~J}$ have been transferred from the rock to the fluid to sustain the boiling. 
In case ( $i i)$ where $100 \%$ of the produced fluid is reinjected, the injected fluid does not significantly influence the production until after about thirty years, the stage at which the reservoir would be exhausted with no injection. The injected fluid being much more dense than the original fluid, with $75 \%$ vapor saturation, occupies a much smaller volume. The pressure gradient required to push the more viscous warm or hot water through the reservoir is not sustained beyond the condensation point where the boiling fluid meets the hot water. The very large effective compressibility in the two-phase region prevents pressure changes at the injection well from influencing the production well.

At thirty years about $50 \%$ of the reservoir has dried out, a small fraction is completely liquid and the rest is boiling (see Figure 11). After this time the production comes from boiling in, and extension of, the twophase region. Some of the water is mobile in the boiling region and therefore it encroaches into the previously superheated region. Also as the pressure over the whole reservoir drops, some of the condensed hot water starts boiling. The overall pressure continues to decline in order to produce enough steam and the gradient in the superheated region around the well steepens once all the mass supply near the well is exhausted. These two effects lead to unacceptably low downhole well pressures at about forty years. At this stage there is still plenty of heat left in the reservoir $\left(48.9 \times 10^{13} \mathrm{~J}\right)$. An interesting feature of the reservoir temperature distribution after thirty years (see Figure 9) is that because heat is being "mined" from the boiling region its temperature drops below that of the superheated steam region surrounding the well.

For case ( $i i i)$, with the injection rate double the production rate, the results are qualitative similar to case ( $i i)$ (see Figure 12). At thirty years, the reservoir has a superheated zone (smaller than in case (ii)), a boiling zone and a large liquid zone. Production is possible for a further 
twenty years during which the boiling zone extends into both the superheated region and the condensed region. The pressure throughout the reservoir declines steadily while the temperature declines most rapidly in the two-phase, boiling zone. At the end of useful production, the energy remaining in the reservoir is still $46.9 \times 10^{13} \mathrm{~J}$ and clearly higher injection rates would increase the longevity of the field still further.

From these cases it is clear that reinjection can extend the life of a two-phase system considerably but it does not increase power output. In fact, because the injected fluid reduces the volume of the boiling zone available for steam production, the production pressure drops slightly faster when more fluid is injected (see Figure 10).

The results obtained here are for an idealized homogeneous, isotropic, thin reservoir. In real reservoirs, fractures and gravity will lead to a preferential movement, with respect to direction or depth, of the injected fluid. The effect of gravity is studied in the next section.

\section{Gravity Segregation}

A numerical study of gravity segregation effects has been completed for a single choice of injection temperature and reservoir saturation. Several different cases were examined for a relatively thick ( 100 meter) plane parallel reservoir. Water at $\approx 33^{\circ} \mathrm{C}$ was injected in a single well with the reservoir initially at a steam saturation of $S=0.75$. Table 1 and 2 summarize the initial conditions for the different problems. The results of the computations are presented in several figures showing some of the most important points. Figure 13 shows the results from Problems 1 and 2 described in Table 2. The figure shows a comparison of the gravity and no gravity cases, and demonstrates dramatically how important gravity segregation effects are when an appreciable amount of steam is present in the reservoir. In these calculations the absolute permeabilities were the same in the horizontal and 
vertical directions. In many cases, the vertical permeability will be considerably less than the horizontal, and will reduce the tendency of the injected fluid to slump to the bottom of the reservoir. Figures 14 and 15 show the corresponding temperatures for Problem 1 . The spreading of the thermal front is a numerical effect due to the coarse mesh $(20 \mathrm{~m})$.

In Figures 16 through 18 the results for Problems 5 and 6 are presented. The calculations show that the injected fluid initially plumes upward, but then the motion is outward and downward through the remainder of the injection period of about 120 days. Obviously there is a relationship between the vertical height of the leading edge and the injection flow rate. At the higher rate the hydrodynamic front is much more spread out with an apparent "second pulse" forming near the well. At the lower rate the liquid simply slumps into the reservoir with a large gravitational effect. This results in a leading edge of liquid at about $3 / 4$ the distance of the higher rate, even though the higher rate is more than twice as great ( 15 compared to $6 \mathrm{~kg} / \mathrm{sec}$ of injected water). Although the liquid advances very quickly near the bottom of the aquifer, the thermal fronts--as shown in Figure 18--1ag far behind. These observations have important implications for production/injection well fields.

Figures 19 and 20 show the results for Problems 3 and 4 . These results, although not carried out as far as the others, show a significant downward migration of fluid, and suggest that the hydrodynamic front will eventually develop more nearly like the full injection case described above.

Due to the large compressibility in the two-phase portions of the reservoir, we do not see a significant pressure increase beyond the hydro-dynamic front. In the case of injection at the top of the reservoir an interesting, but relatively unimportant, pressure effect occurs. Due to the slumping, condensing liquid, the pressure decreases slightly at the top of the reservoir near the hydrodynamic front, which results in a few percent increase in steam saturation locally. 
Since a coarse grid was used for these calculations ( $20 \times 20 \mathrm{~m})$, a number of questions remain regarding. numerical effects on the detailed front propagation. These questions were outside the scope of these investigations.

\section{One-Dimensional Approximation of Lardere110}

We consider a one-dimensional vertical system with porosity. Figure 21 shows our idealized system and the corresponding real reservoir. Reservoir properties and thermodynamic conditions are similar to those encountered in the most depleted zones of Larderello.

The wells produce from a fracture system at the top of the reservoir. The fracture system is presumed to make the pressure uniform at the top and equal to bottomhole values in the productive wells. The steam produced by the boiling water in the deeper layers rises vertically to collect in the fractures at the top of the reservoir. Initial conditions are given in Figure 22. Pressure is maintained practically constant at the top and bottom boundaries by connecting the system with ficticous elements having very large volumes. The system remains practically steady in these conditions with a steam production rate of $17 \mathrm{~kg} /\left(\mathrm{sec} \cdot \mathrm{km}^{2}\right)$. An injected flowrate of $20 \mathrm{~kg} /\left(\mathrm{sec} \cdot \mathrm{km}^{2}\right)$ of water at $30^{\circ} \mathrm{C}$ was simulated at different depths (Figure 23).

It has already been noted that in problems involving sharp fronts and phase transitions, simulation produces oscillating trends of a certain size and that these oscillations are a consequence of finite space discretization. 34 These oscillations occur in all our examples of water injection into regions of the reservoir where $P<P_{\text {sat }}$. They derive from finite discretization and from the hypothesis that, in each point of the reservoir, the rock and fluid are at all times in thermal equilibrium.

Figure 24 shows the trend of the production flow rate and some quantities in the grid elements near the injection point. This refers to case a) of 
Figure 23 where the thickness of the elements around the injection point is $3 \mathrm{~m}$. In this example, boundary pressure at the bottom is a little higher than in Figure 22 .

As the injected water enters element no. 1 , it is soon vaporized, the rock and fluid both having the same temperature at all times. This continues until saturation conditions are reached in the element. From this moment on not all the water is vaporized, the production rate begins to decrease, and liquid saturation increases in the element. Subsequently the behavior of the model is controlled by the following phenomena:

- liquid water flows gravitationally (in this case) from one element to the underlying one each time the immobile water saturation is exceeded in the former;

- all the liquid water entering an element is vaporized until saturation conditions are reached in it;

- vaporization (and, hence, production) starts to increase whenever the liquid penetrates a new element in which $P<P_{\text {sat }}$.

- vaporization begins decreasing whenever a new element reaches saturation conditions.

The amplitude and frequency of the oscillations depends on space discretization, on the difference between initial temperature and saturation temperatures in the elements penetrated by the liquid water, on the pressure variations in these elements, and on the shape of the relative permeability curves for the two phases.

Our simulation tests have always shown that a finer space discretization will reduce the amplitude and increase the frequency of the oscillations. Moreover, in the case of discretizations that are not too coarse, the oscillations all occur around an average curve; the result of numerical simulation gradually approaches this curve as the space discretization becomes finer (see Figure 25, relative to the same case as Figure 24). 
The relative permeability of the two phases is a very important parameter for reinjection as it affects both the pressure gradient and 1iquid propagation through the rock volume. Unfortunately, there would appear to be no safe criteria at present for attributing one given relative premeability curve to the various reservoir rocks. Figure 26 shows some theoretical and empirical curves.

Curve a) was obtained from a version of Corey's equation.

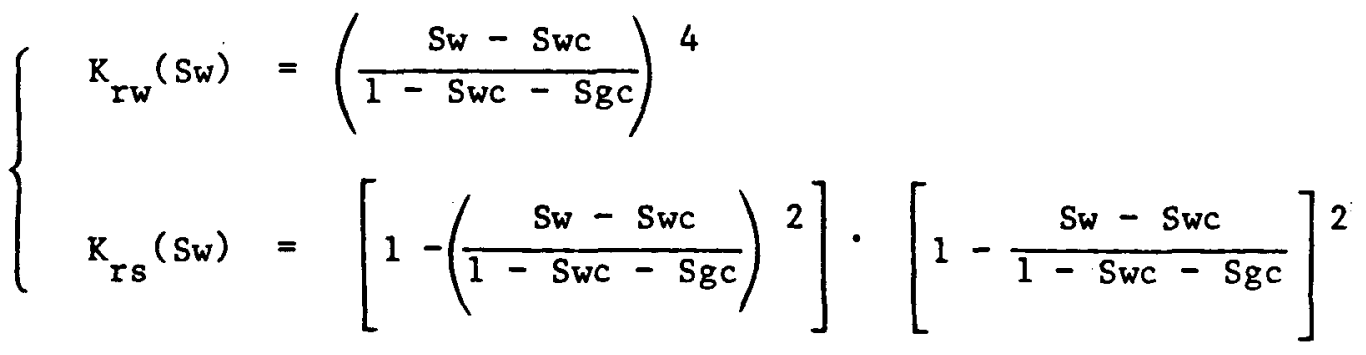

$$
\begin{aligned}
& \text { for } S_{w c}<S_{w}<1-S_{g c} \\
& \left.\begin{array}{l}
K_{r w}=0 \\
K_{r S}=1
\end{array}\right\} \quad \text { for } S w \leq S w c \\
& \left.\begin{array}{l}
K_{I W}=1 \\
K_{I S}=0
\end{array}\right\} \quad \text { for } S w \geq 1-S g c \\
& \text { with Swc }=0.3, \mathrm{Sgc}=0 \text {. }
\end{aligned}
$$

This is the parametrization generally used in our one-dimensional model. Curve b) is derived from Wairakei production data. The parabolic curves in Figure $26 \mathrm{c}$ were used by some authors to simulate two-phase reservoirs 35 , while curves d) were based on preliminary laboratory results obtained at Stanford University. 36 These curves were taken as an example of just how varied they can be.

The model's behavior is strongly affected by the choice of relative permeabilities. Usually a high $\mathrm{K}_{\mathrm{rw}}$ for low water saturation values attenuates the discretization effects mentioned earlier. Figure 27 , relative to the case 
of Figure 24 with a $3 \mathrm{~m}$ space discretization in the injection zone, shows that the oscillations are greatly reduced with the "Wairakei curve". While the oscillations in the two curves derive from finite space discretiztion, the difference in average production rate from one case to the next is a result of a difference in behavior of reservoirs with different relative permeability curves. In the case of curve b), the period of injection being equal, the liquid propagates through a larger rock volume, which thus implies higher boiling rates.

Figure 28 shows the variations in production rate coming from injecting $20 \mathrm{~kg} /\left(\mathrm{sec} \cdot \mathrm{km}^{2}\right)$ at different depths.

The production rate increase clearly diminishes when injection is made at greater depth. Injection into the saturated zone even brings about a slight production decrease.

Considering cases a), b), and c) only, the variation of production with depth of injection is due to the following facts:

- vaporization of the injected water produces a pressure increase in the injection zone, with a consequent increase in the gradient above and reduction in that below this zone. Vaporization of injected water, therefore, contributes to production, but also reduces the contribution from deep boiling;

- the fluid state in the deep horizons is nearer the saturation then in shallower layers;

- the liquid saturation build-up in the injection zone reduces the relative permeability to steam;

- the pressure increases below the injection horizon. In the parts of the reservoir containing two-phase fluid even a small pressure increase can stop boiling and start condensation.

Figure 29 shows the evolution of saturation around the injection point in cases a) and c). In the latter, more liquid accumulates in the injection 
zone. Furthermore, while the liquid flows downwards by gravity in the higher permeability formations, the pressure gradient in the low permeability deep formations is high enough to overcome gravity and the liquid is carried upwards. Obviously a one-dimensional model can reproduce only part of the phenomenology of a three-dimensional reservoir with distant injection wells. However, the results of this simplified model are in agreement with the observations made at Larderello with regard to shallow and deep injection. In all these examples, the temperature of the steam produced at the top of the reservoir remains practically constant. This is due to the fact that the steam produced from injected water (after mixing with steam from deep boiling) crosses a hot rock layer unaffected by boiling. Usually it is desirable that the steam produced from injected water crosses a certain interval of hot rock before reaching the producing wells. If the injection point is too near the extraction point, the thermodynamic characteristics of the fluid are adversely affected, with the risk of efficiency reduction in the conversion phase. On the other hand, if too large rock volumes are left out of injection, this may cause a reduction in recovery of the reserves.

\section{Conclusions}

Injection into a two-phase reservoir usually prolongs its economic production and increases the recovery factor, but may decrease the production rate in the short-term. In a field such as Larderello, which has been exploited over a very long period without reinjection, the conditions are now such as to permit a higher long-term recovery as well as increased short-term production. In favorable situations this can be obtained without detrimental effects on the thermodynamic characteristics of the fluid produced. As the injected water contains minimal amounts of noncondensable gas and is quickly vaporized, the chemical characteristics of the steam produced may even improve, to the advantage of conversion efficiency. 
The application of numerical simulation to the study of reinjection problems reveals how useful this approach can be, even though it is confined for the moment to ideal systems or particular problems. There have been too few field data available so far to show whether the model of the porous medium is capable of simulating fractured reservoirs in which rock-fluid heat exchange is the dominating phenomenon.

Similarly the lack of information on relative permeability, which also has a strong influence on the phenomena, prevents formation of fully reliable models. Field and laboratory tests will consequently play an important role in the near future. Particularly important is to identify, in the geothermal field, the zones in which $P<P_{\text {sat }}$, the volumes involved, and the reservoir characteristics. Injection itself could be used for this purpose. Simulation of injection in a reservoir whose fluid is superheated steam poses some problems: a very fine space descretization must be used and the time step must also be shortened when crossing the saturation line in the water equation of state diagram. However, it is felt that approximate results acceptable to the engineer can be achieved even in these circumstances at a reasonable cost. Finally, it should be noted that $P<P_{\text {sat }}$ does not always imply that only superheated steam exists in the porous medium. Vapor pressure lowering can be produced by salinity, capillarity, and adsorption phenomena. These phenomena also require more detailed study.

In summary, our investigations to date result in the following general conclusions :

1. Numerical simulation is a valid and viable tool for studying injection into two-phase reservoirs.

2. Injection well tests in thin formations can be analyzed by means of single-phase pressure transient techniques.

3. Injection into a producing two-phase reservoir may enhance 
ultimate energy recovery by large amounts, with small effects on power output.

4. Gravity effects can be very strong in thick reservoirs.

5. Injection into superheated steam zones may increase production rates as well as energy recovery.

It is suggested that future work on modeling injection should investigate the effects of fractures. Also, efforts should be made for modeling actual field cases rather than idealized problems. 
$\underline{\text { References }}$

1. A.J. Chasteen, Geothermal Steam Condensate Reinjection, Vo1. 2, Proceedings Second United Nations Symposium, San Francisco, California (May, 1975).

2. G. Cuellar, Behavior of Silica in Geothermal Waste Waters, Ibid.

3. S.S. Einarsson, A. Vides R., and G. Cuellar, Disposal of Geothermal Waste Water by Reinjection, Ibid.

4. P.A. Witherspoon, Unpublished reports.

5. K. Kubota, K. Aosaki, Reinjection of Geothermal Hot Water at the Ot ake Geothermal Field, Vo1. 2, Proceedings Second United Nations Symposium, San Francisco, California (May, 1975).

6. R. Schroeder, Unpublished data.

7. S.M. Benson, C.B. Goranson, D. McEdwards, and R.C. Schroeder, Well Tests, In: Geothermal Resource and Reservoir Investigation of U.S. Bureau of Reclamation Leaseholds at East Mesa, Imperial Valley California, Report 非BL-7094 (October 1978).

8. C.F. Knutson and C.R. Broadman, An Assessment of Sub-Surface Salt Water Disposal Experience on the Texas and Louisiana Gulf Coast, Report No. EY-77-C-08-1531 (1977).

9. J.S. Aronofsky and H.J. Ramey, Jr., Mobility Ratio -- Its Influence on Injection or Production Histories in Five-spot Waterflood, Petroleum Transactions, AIME Journal, Vol. 207, p. 205 (1956).

10. J.S. Brown and H.W. Engelhardt, A Case Study of Startup Management for a Large Seawater Injection Project, SPE Paper 8409 , presented at the 54th Annual Fall Technical Conference, Las Vegas, Nevada, September, 1979 .

11. G. Bodvarsson, Thermal Problems in the Siting of Reinjecting Wells, Geothermics Vol. 1, no. 2 (1972).

12. G. Bodvarsson, On the Temperature of Water Flowing through Fractures, J. Geophys. Res., Vol. 74, No. 8 (April, 1969).

13. A.C. Gringarten, P.A. Witherspoon, and Y. Onishi, Theory of heat Extraction From Fractured Hot Dry Rock, J. Geophys. Res., Vol. 80, No. 8 (March, 1975).

14. P. Kasameyer and R. Schroeder, Thermal Depletion of Liquid-Dominated Geothermal Reservoirs with Fracture and Pore Permeability, UCRL-77323 preprint (December, 1975).

15. G.S. Bodvarsson, C.F. Tsang, Injection Into a Fractured Geothermal Reservoir, Transactions, Vol. 4, Geothermal Resources Council (September, 1980). 
16. A.C. Gringarten, J.P. Sauty, The Effect of Reinjection on the Temperature of a Geothermal Reservoir Used for Urban Heating; Proceedings, Second United Nations Symosium, San Francisco, California (May, 1975).

17. P.W. Kasameyer, Thermal History of Reinjected Effluents (Unpublished), (August, 1976).

18. T.W. Tsang and C.F. Tsang, An Analytical Study of Geothermal Reservoir Pressure Response to Cold Water Reinjection, Proceedings Fourth Workshop Geothermal Reservoir Engineering, Stanford University (1978).

19. M.J. Lippmann, C.F. Tsang, and P.A. Witherspoon, Analysis of the Response of Geothermal Reservoirs under Injection and Production Procedures, SPE-6537, Presented at the 47th Regional Meeting of the SPE, Bakersfield, California (1977).

20. M.J. O'Sullivan and K. Pruess, Analysis of Injection Testing of Geothermal Reservoirs, Vol. 4, Geothermal Resources Council (September, 1980).

21. M. Nathenson, Physical Factors Determining the Fraction of Stored Energy Recoverable from Hydrothermal Convection Systems and Conduction-dominated Areas, U.S. Geological Survey Open-file Report 75-525 (October, 1975).

22. D. Mangold, C.F. Tsang, M.J. Lippmann and P.A. Witherspoon, A Study of Thermal Effects in Well Test Analysis, SPE Paper 8232, presented at 54th Annual Fall Meeting SPE, Las Vegas (September, 1979).

23. J.W. Pritchett, S.K. Garg, and T.D. Riney, Numerical Simulations of the Effects of Reinjection on Performance of a Geopressured Geothermal Reservoir, Geothermal Resource. Council Transaction, Vol. 1 (1977).

24. K. Pruess and R.C. Schroeder, Geothermal Reservoir Simulations with SHAFT79, Proceedings Fifth Workshop Geothermal Reservoir Engineering, Stanford University (December 1979).

25. L.D. Mlodinow and C.F. Tsang, The Effect of Radially Varying Transmissivity on the Transient Pressure Phenomenon, Proceedings Third Workshop Geothermal Reservoir Engineering, Stanford University (December, 1977).

26. R.J. Blackwell, J.R. Rayne, and W.M. Terry, Factors Influencing the Efficiency of Miscible Displacement, Petroleum Transactions Reprint Series, No. 8, Miscible Processes, SPE.

27. T.K. Perkins and O.C. Johnston, A Review of Diffusion and Dispersion in Porous Media, Ibid.

28. J.P. Sauty, A.C. Gringarten, and P.A. Landel, The Effect of Thermal Dispersion on Injection of Hot Water in Aquifers. Proceedings of the Second Invitational Well Testing Symposium (October, 1978). 
29. J.P. Sauty, An Analysis of Hydrodispersive Transfer in Aquifers, Water Resources Research, Vol. 16, No. 1, p. 145-158 (February 1980).

30. J.E. Warren and P.J. Root, The Behavior of Naturally Fractured Reservoirs, S.P.E.J., Vol. 3, p. 245-255 (1963).

31. P.A. Witherspoon, J.S.Y. Wang, K. Iwai, and J.E. Gale, Validity of the Cubic Law for Fluid Flow in Deformable Rock Fracture, Report 非BL-9557 (1979).

32. G.S. Bodvarsson and C.F. Tsang, Injection Into Geothermal Fractures, Proceedings of the Third Invitational Well Test Symposium (to be published, 1980).

33. S.K. Garg, Pressure Transient Analysis for Two-phase (Liquid Water/Steam) Geothermal Reservoirs, paper SPE-7479, presented at the 53rd Annual Fall Technical Conference and Exhibition of the Society of Petroleum Engineers, Houston, Texas (October, 1978).

34. K. Pruess, G. Bodvarsson, R.C. Schroeder, P.A. Witherspoon, R. Marconcini, G. Neri, and C. Ruffilli, Simulation of the Depletion of Two-Phase Geothermal Reservoirs, Paper SPE-8266, presented at the 54th Annual Fall Technical Conference and Exhibition of the SPE, Las Vegas, Nevada (September 1979).

35. S.R. Aydelotte, Transient Well Testing in Two-Phase Geothermal Reservoirs, Lawrence Berkeley Laboratory Report LBL-10562, Berkeley, California (March 1980).

36. J.R. Counsil and H.J. Ramey, Jr., Drainage Relative Permeabilities Obtained from Steam-Water Boiling Flow and External Gas Drive Experiments, Transactions, Geothermal Resources Council, Vol. 3 (September 1979).

37. C.R. Faust and J.W. Mercer, Geothermal Reservoir Simulation, 2. Numerical Solution Techniques for Liquid - and Vapor - Dominated Hydrothermal Systems, Water Resources Research, Vol. 15, No. 1, p. 31-45 (February 1979). 


\section{APPENDIX}

Consider injection of cold water with temperature $T_{\text {in }}$ at constant rate $q$ into a thin infinite two-phase reservoir with uniform initial conditions (temperature: $T_{\text {res }}$, vapor saturation $S$ ). We postulate that the process will give rise to a sharp temperature front, where reservoir temperature changes from $T_{i n}$ to $T_{r e s}$, and proceed to estimate total swept volume $V_{S}$ and volume of the cold zone, $v_{c}$.

Neglecting the density of steam in comparison to that of liquid water, we have for the total injected mass:

$$
M=q t=v_{s} \phi S \rho_{w}^{\prime}+v_{c} \phi\left(\rho_{w}-\rho_{w}^{\prime}\right)
$$

where $\rho_{w}$ and $\rho_{w}$ are liquid water densities at injection temperature $T_{\text {in }}$ and reservoir temperature $\mathrm{T}_{\text {res }}$, respectively.

For the total internal energy of the swept volume we have:

$$
\begin{aligned}
E= & v_{c}\left[\phi \rho_{w} C_{w}+(1-\phi) \rho_{R} C_{R}\right] T_{\text {in }} \\
& +\left(v_{S}-v_{c}\right)\left[\phi \rho_{w} C_{w}+(1-\phi) \rho_{R} C_{R}\right] T_{\text {res }}
\end{aligned}
$$

This is approximately equal to the total internal energy present in swept volume and injection fluid separately (neglecting small steam contributions):

$$
E \simeq V_{S}(1-\phi) \rho_{R} C_{R} T_{\text {res }}+M_{w} T_{i n}+V_{S} \phi(1-s) \rho_{w}^{\prime} C_{w} T_{\text {res }}
$$

from which:

$$
\frac{v_{c}}{V_{S}}=\frac{S \phi \rho_{w}^{\prime} C_{w}}{\phi \rho_{w}^{\prime} C_{w}+(1-\phi) \rho_{R} C_{R}}
$$

also,

$$
v_{s}=\frac{M}{\phi S \rho_{w}^{\prime}+\left(v_{c} / v_{S}\right) \phi\left(\rho_{w}-p_{w}^{\prime}\right)}
$$


The location of the thermal front can be used to estimate porosity, in the following way. At time $t$, the total amount of injected fluid is qt. of this, an amount $V_{c} \phi P_{w}$ is still at injection temperature, while an amount ( $q t-v_{c} \phi p_{w}$ ) has moved on and has been heated up to $T_{\text {res }}$. Assuming that the energy transferred to the fluid was supplied by the cooled rock, we have:

$$
\left(q t-v_{c} \phi \rho\right) C_{w}\left(T_{\text {res }}-T_{\text {in }}\right)=v_{c}(1-\phi) \rho_{R} C_{R}\left(T_{\text {res }}-T_{\text {in }}\right)
$$

from which, using $v_{c}={ }^{2} R_{c}{ }^{2} H$ :

$$
\frac{\frac{{ }^{q C} C_{w}}{\pi_{H}} \frac{t}{R_{C}^{2}}-\rho_{R} C_{R}}{\rho_{w} C_{w}-\rho_{R} C_{R}}
$$


TABLE 1: Parameters used in Injection Simulation

PROBLEM

1-D RADIAL FIVE-SPOT 2-D VERTICAL

Rock density $\rho_{\mathrm{r}}\left(\mathrm{kg} / \mathrm{m}^{3}\right)$

Rock specific heat $\mathrm{C}_{\mathrm{r}}\left(\mathrm{J} / \mathrm{kg}^{\circ} \mathrm{C}\right)$

Rock heat conductivity $\mathrm{K}_{\mathrm{r}}\left(\mathrm{W} / \mathrm{m}^{\circ} \mathrm{C}\right)$

Porosity $\phi(\%)$

Permeability $\mathrm{k}\left(10^{-15} \mathrm{~m}^{2}\right)$

Residual immobile water saturation $S_{w c}$ *

Residual immobile team saturation $\mathrm{S}_{g_{c}}$ *

Reservoir thickness (m)

Initial reservoir temperature $\left({ }^{\circ} \mathrm{C}\right)$

Initial vapor saturation (\%)

Injection enthalpy $(\mathrm{J} / \mathrm{kg})$

Injection temperature $\left({ }^{\circ} \mathrm{C}\right)$

Injection rate $(\mathrm{kg} / \mathrm{sec})$

Production rate $(\mathrm{kg} / \mathrm{sec})$

\begin{tabular}{ccc}
2600 & 2600 & 2600 \\
770 & 755 & 755 \\
2.0 & 2.1 & 2.1 \\
15 & 10 & 10 \\
240 & 40 & 40 \\
.30 & .40 & .40 \\
.05 & 0.0 & 0.0 \\
1 & 10 & 100 \\
233.8 & 240 & 240 \\
20 & 75 & 75 \\
421938 & 147000 & 33.0 \\
100.1 & 40.0 & $6.0,15.0$ \\
\hline-40358 & $0.0,0.025,0.05$ & -1300 \\
\hline- & 0.025 &
\end{tabular}

*Corey's equations as given in Equation 5 were used for relative permeabilities 
TABLE 2: Injection Parameters

\begin{tabular}{lcccccc}
\hline Case number & 1 & 2 & 3 & 4 & 5 & 6 \\
Gravity (m/sec & & & & & & \\
& 0 & 9.81 & 9.81 & 9.81 & 9.81 & 9.81 \\
Open interval & $100 \mathrm{~m}$ & $100 \mathrm{~m}$ & $\begin{array}{c}\text { top } \\
40 \mathrm{~m}\end{array}$ & $\begin{array}{c}\text { top } \\
40 \mathrm{~m}\end{array}$ & $\begin{array}{c}\text { bottom } \\
40 \mathrm{~m}\end{array}$ & $\begin{array}{c}\text { bot tom } \\
40 \mathrm{~m}\end{array}$ \\
$\begin{array}{l}\text { Injection rate } \\
(\mathrm{kg} / \mathrm{sec})\end{array}$ & 15 & 15 & 15 & 6 & 15 & 6 \\
\hline
\end{tabular}




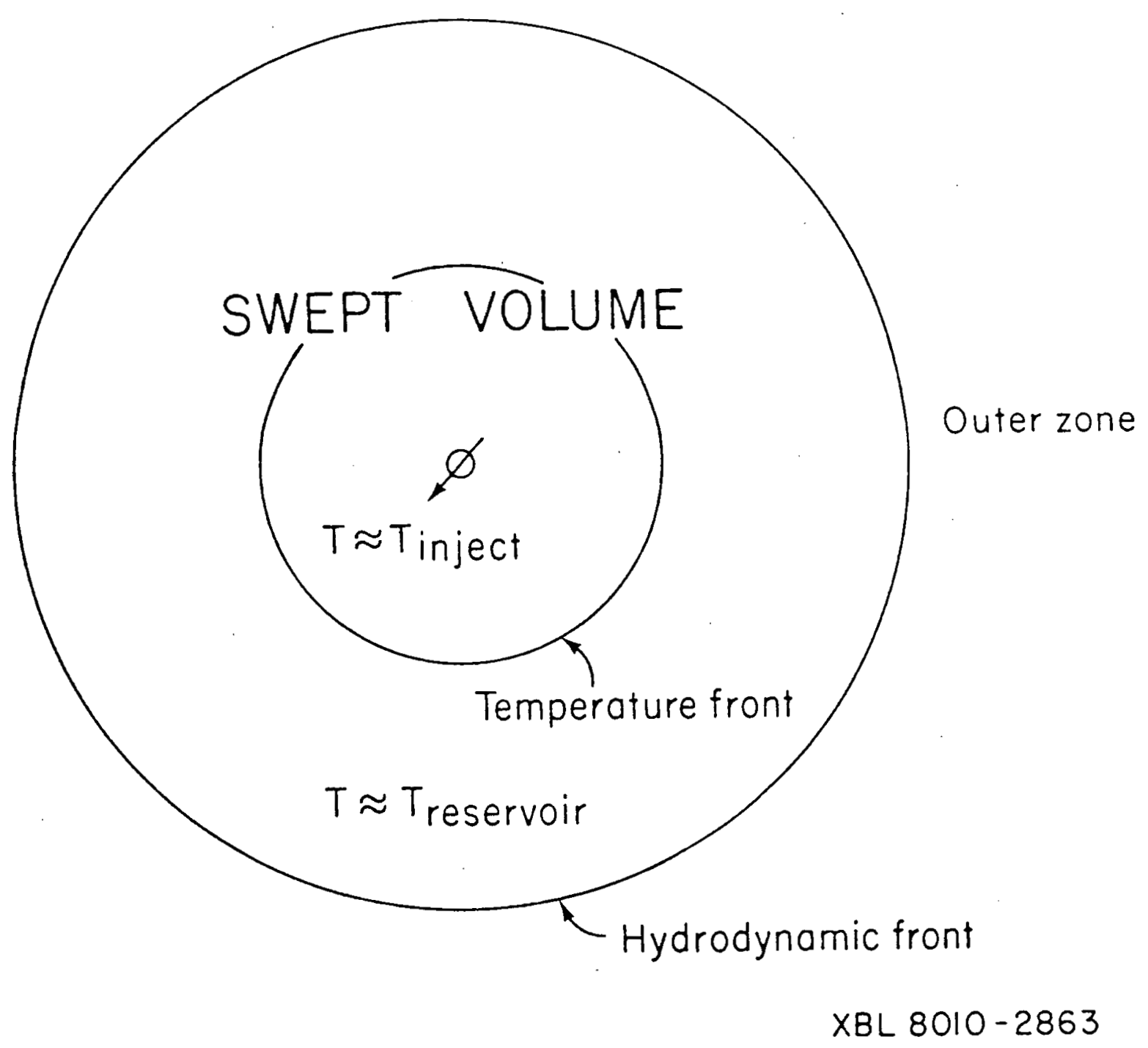

Figure 1. Fronts in a typical injection problem. 

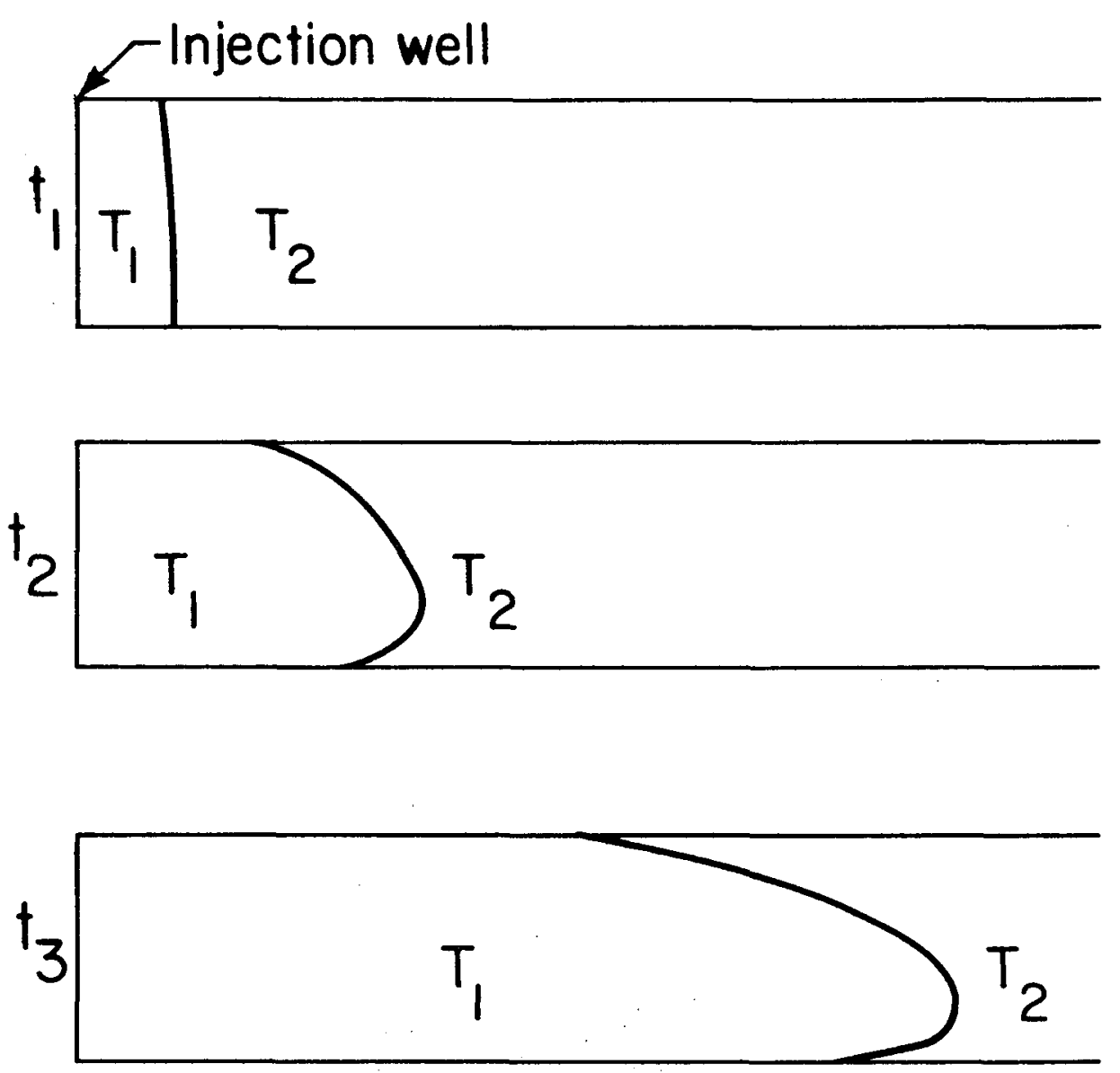

Figure 2. Injection of cold fluid into a thick reservoir. 


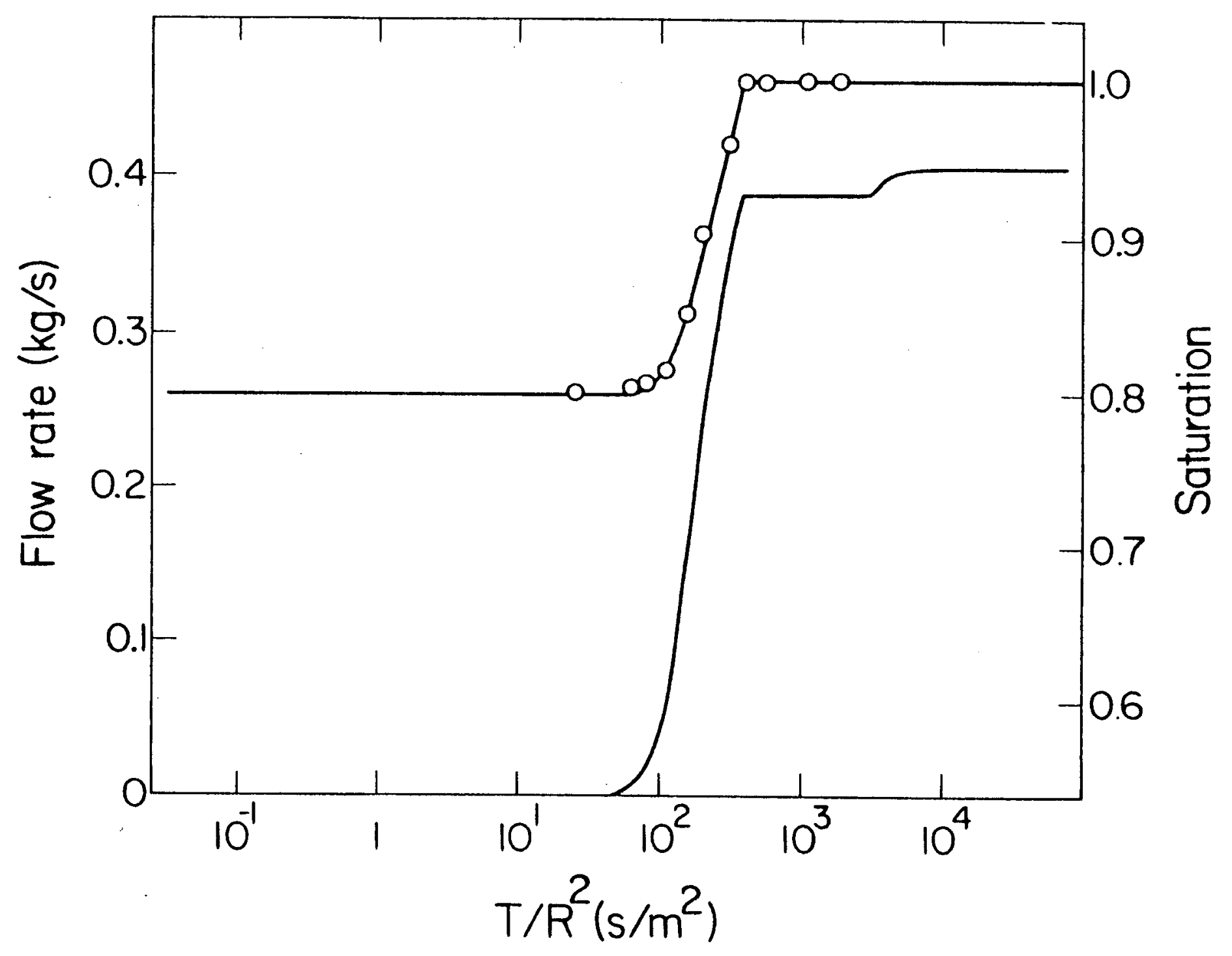

Figure 4. Flowrate and saturation profiles for injection of cold water into a two-phase reservoir. Simllarity method results 20 are shown - and SHAFT 79 results as 0. 


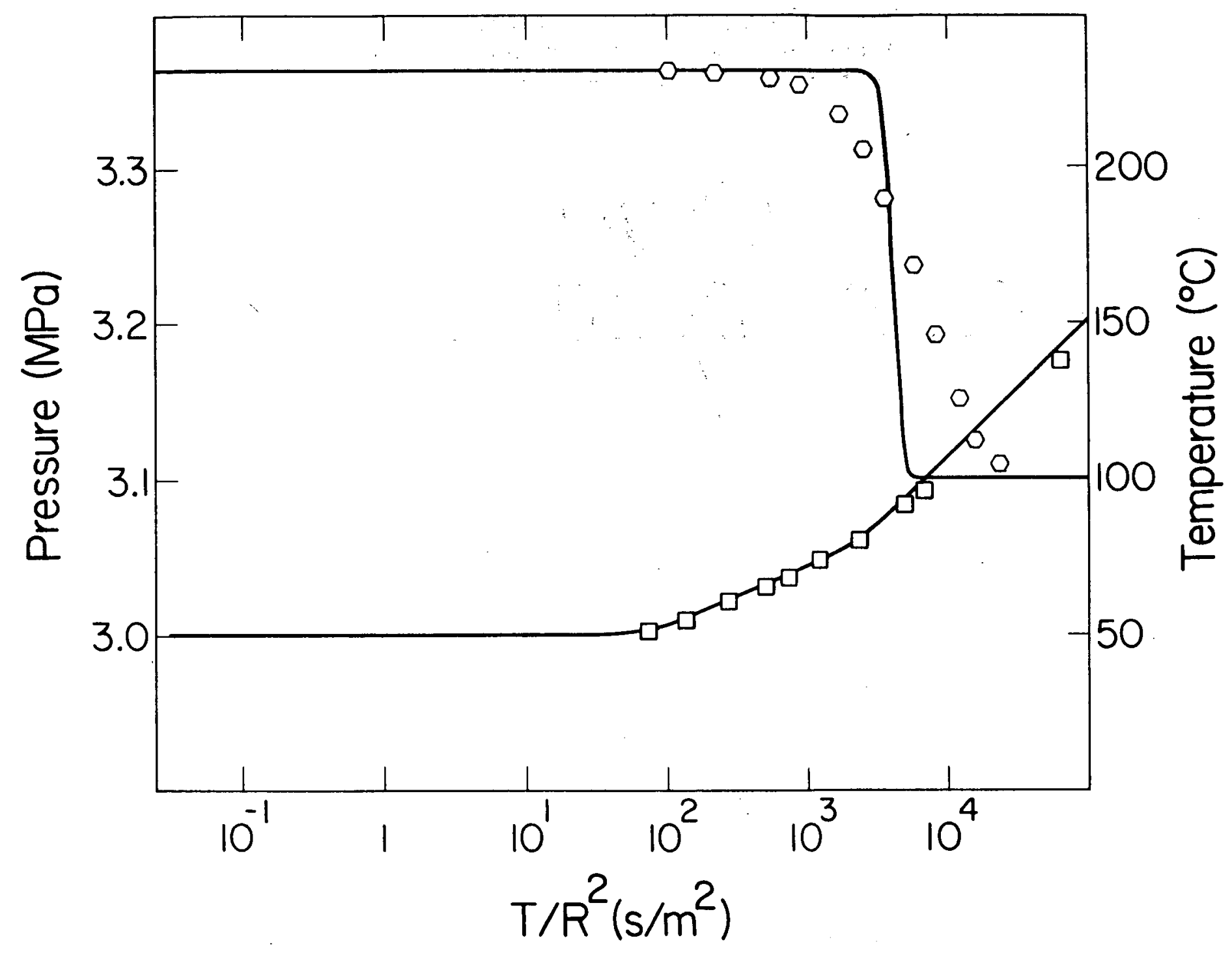

Figure 5. Temperature and pressure profiles for injection of cold water into a two-phase reservoir. Similarity method results 20 are shown as and SHAFT 79 results as $\square$ for pressures and $O$ for temperatures. 


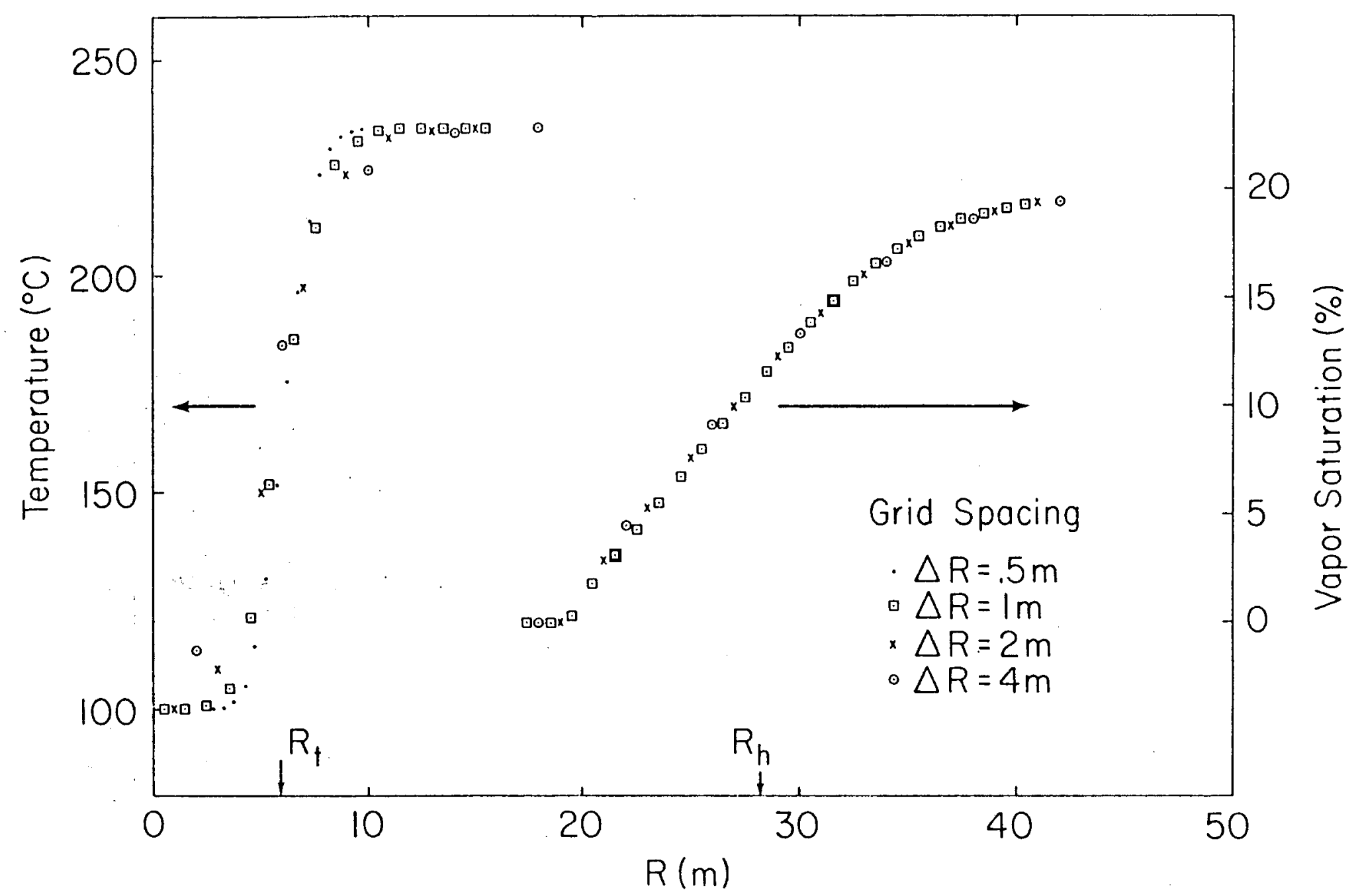

XBL $8010-2862$

Figure 6. Thermal and hydrodynamic fronts for the radial injection problem at $t=160,000$ seconds. 


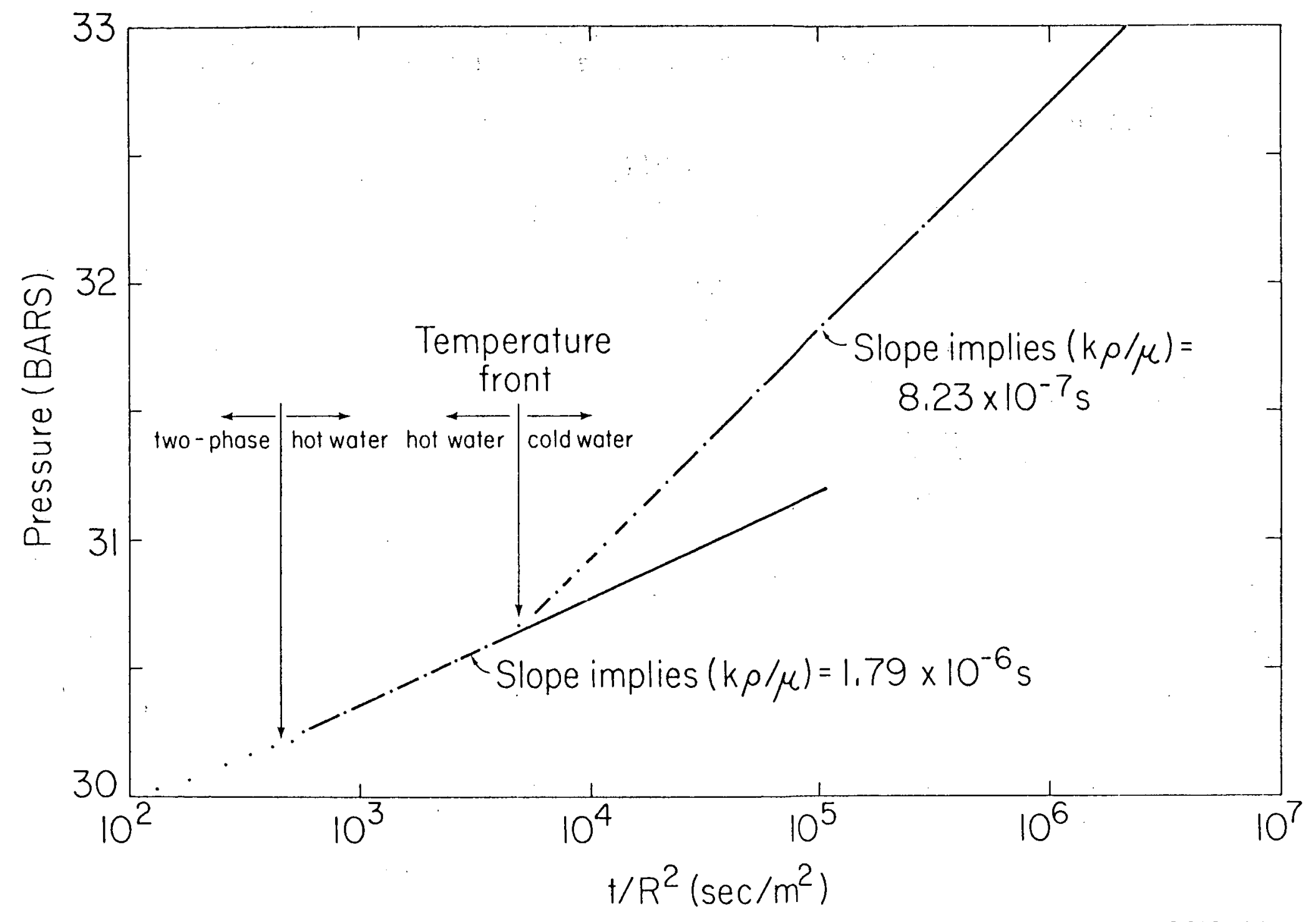

Figure 7. Simulated pressures for radial injection problem. 


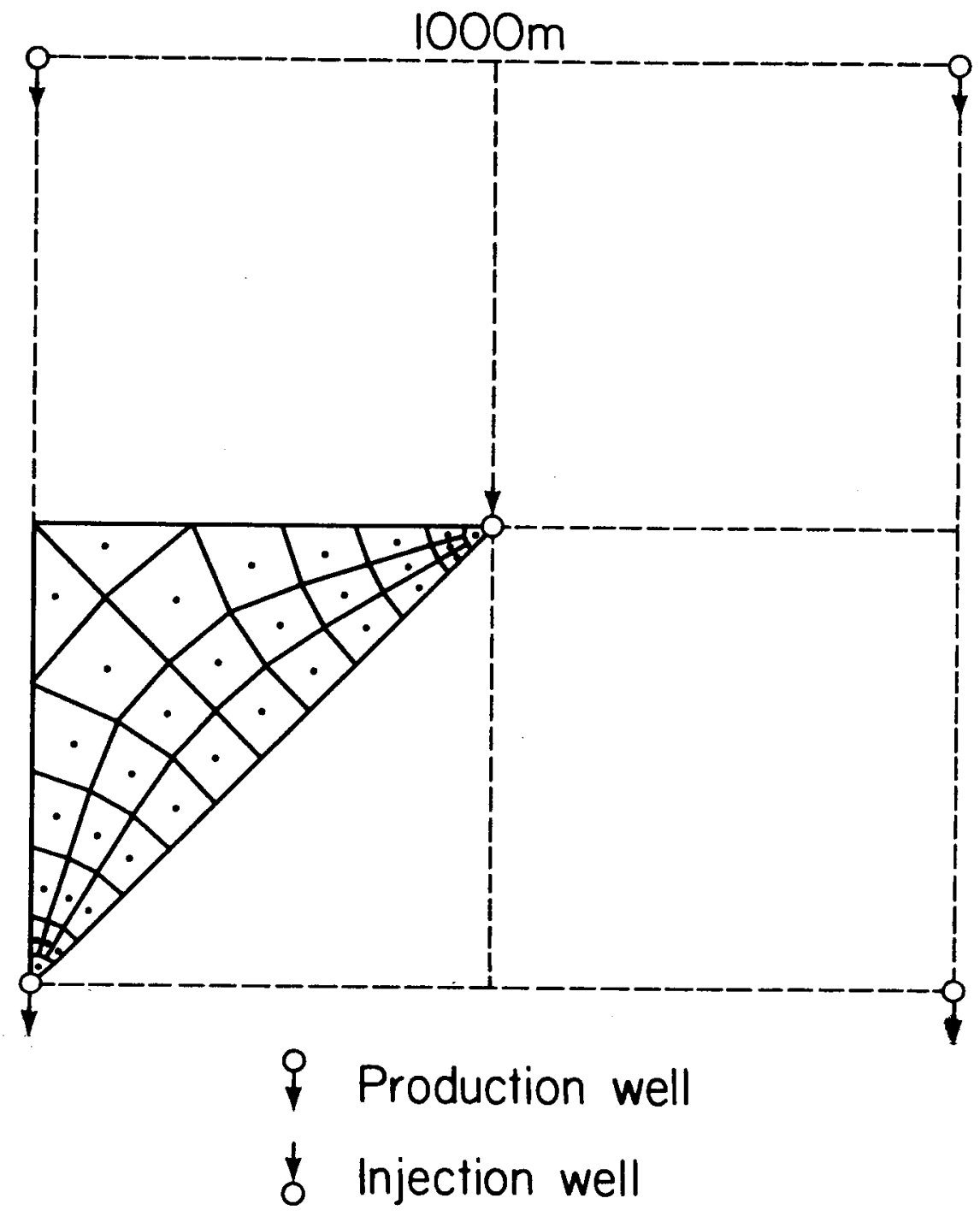

Figure 8. The configuration of production and injection wells and the computational grid for the five-spot problem. 


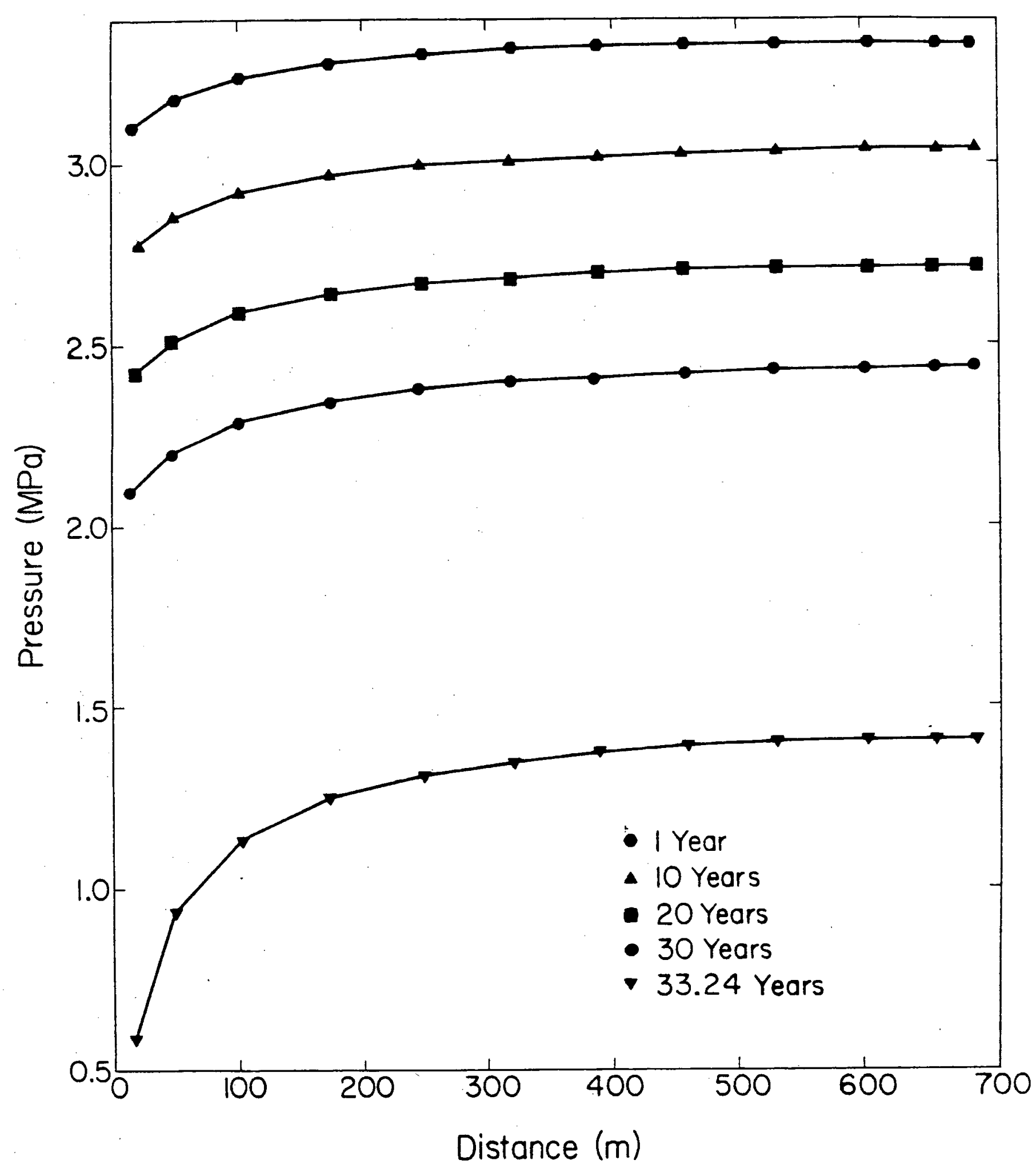

Figure 9a. Pressure profiles along a line jolning the production and injection wells for the five-spot problem. Infection rate $0.0 \mathrm{~kg} / \mathrm{sec}$. 


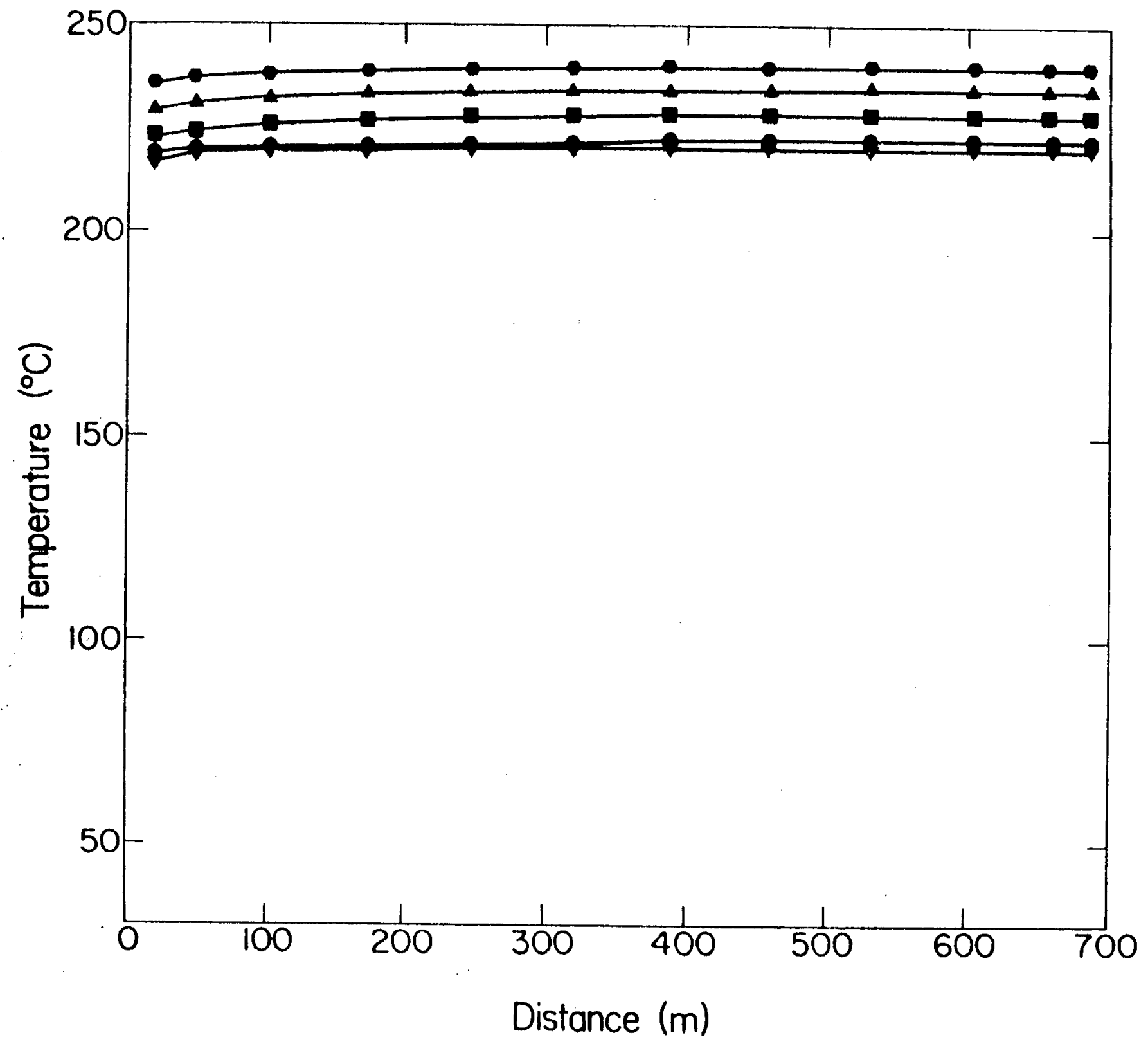

Figure 9b. Temperatures profiles along a line joining the production and injection wells for the five-spot problem. Injection rate $0.0 \mathrm{~kg} / \mathrm{sec}$. 


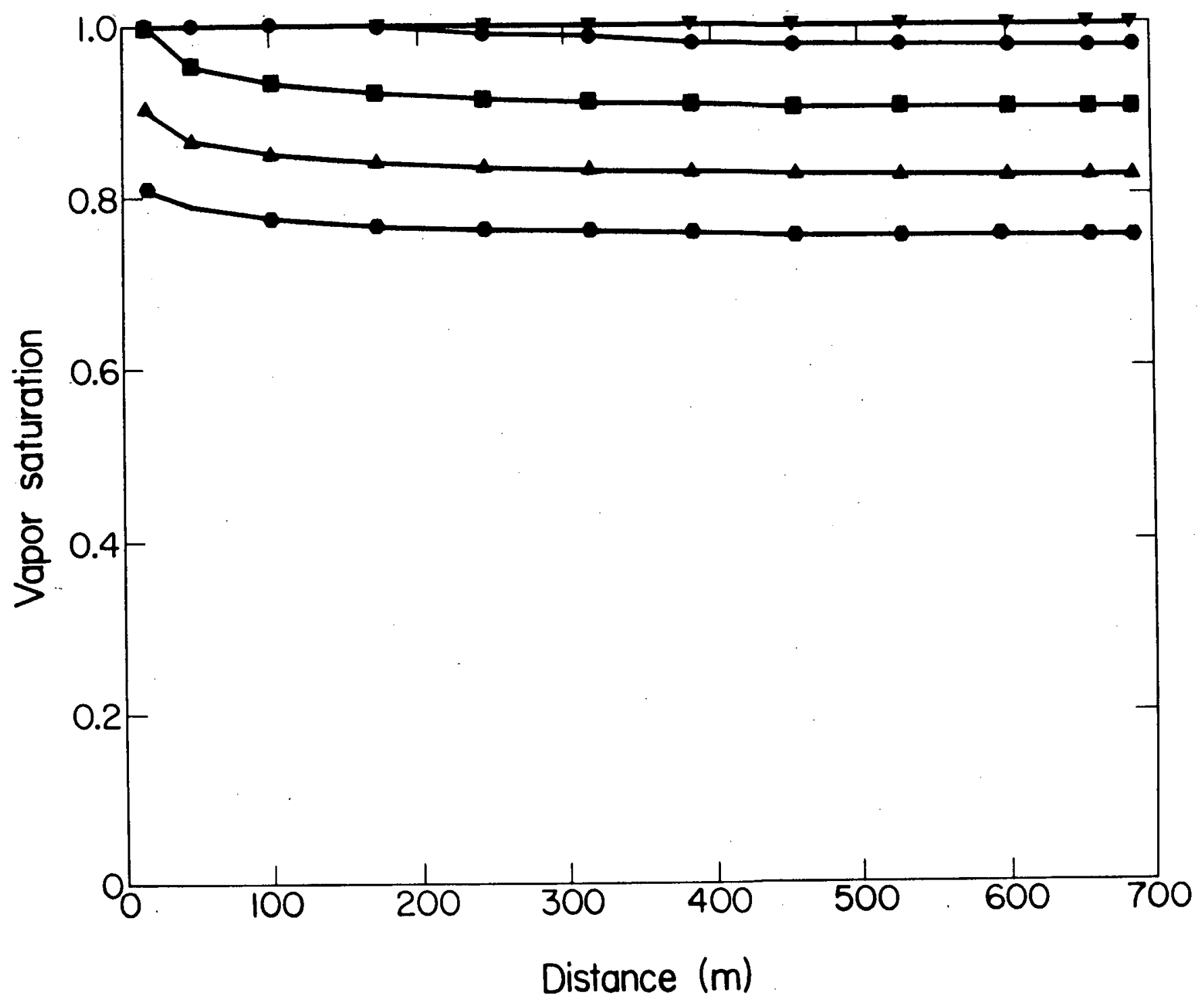

Figure 9c. Vapor saturation profiles along a line joining the production and injection wells for the five-spot problem. Injection rate $0.0 \mathrm{~kg} / \mathrm{sec}$. 


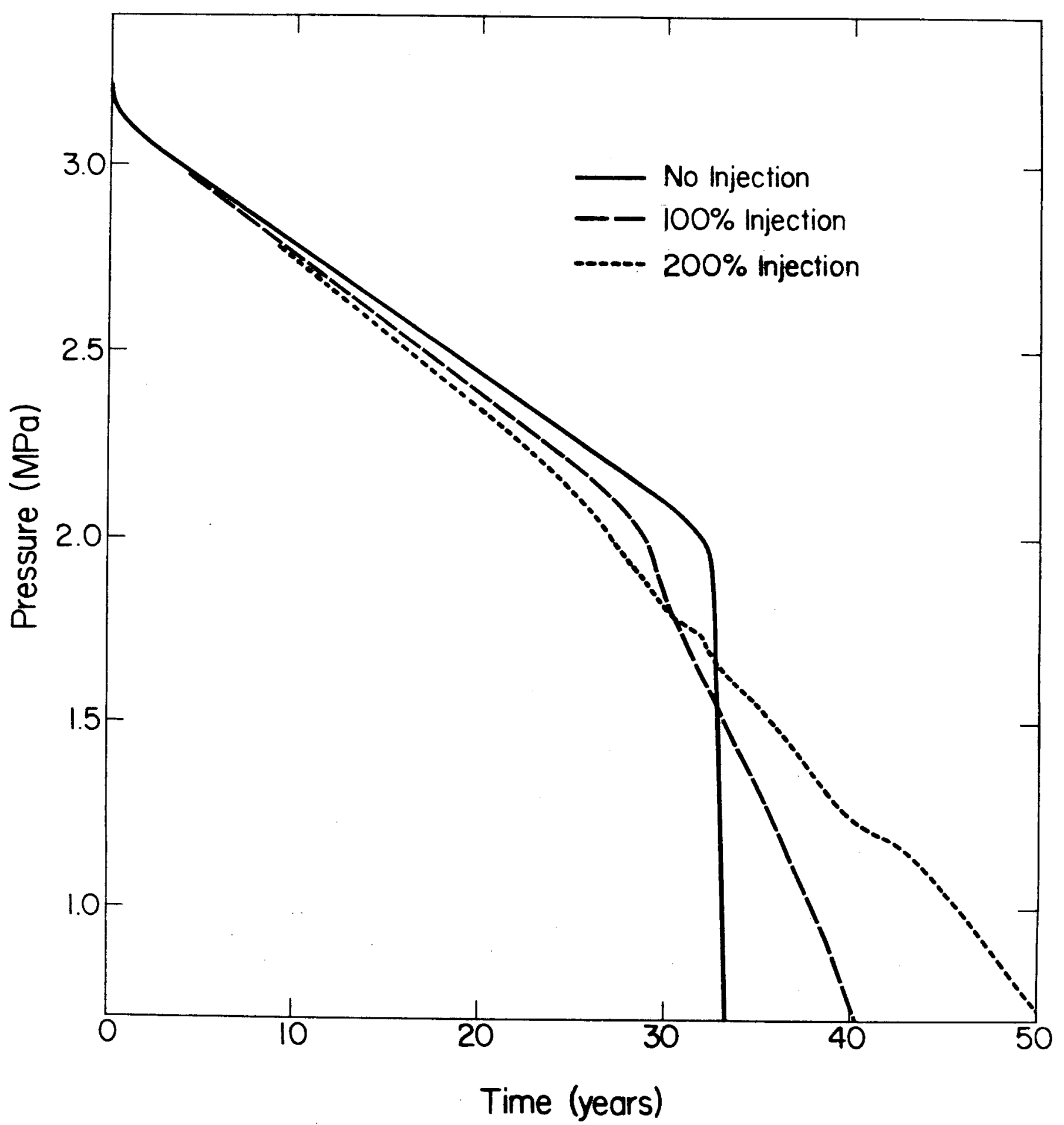

Figure 10. Pressure decline in the production block for the five-spot problem. 


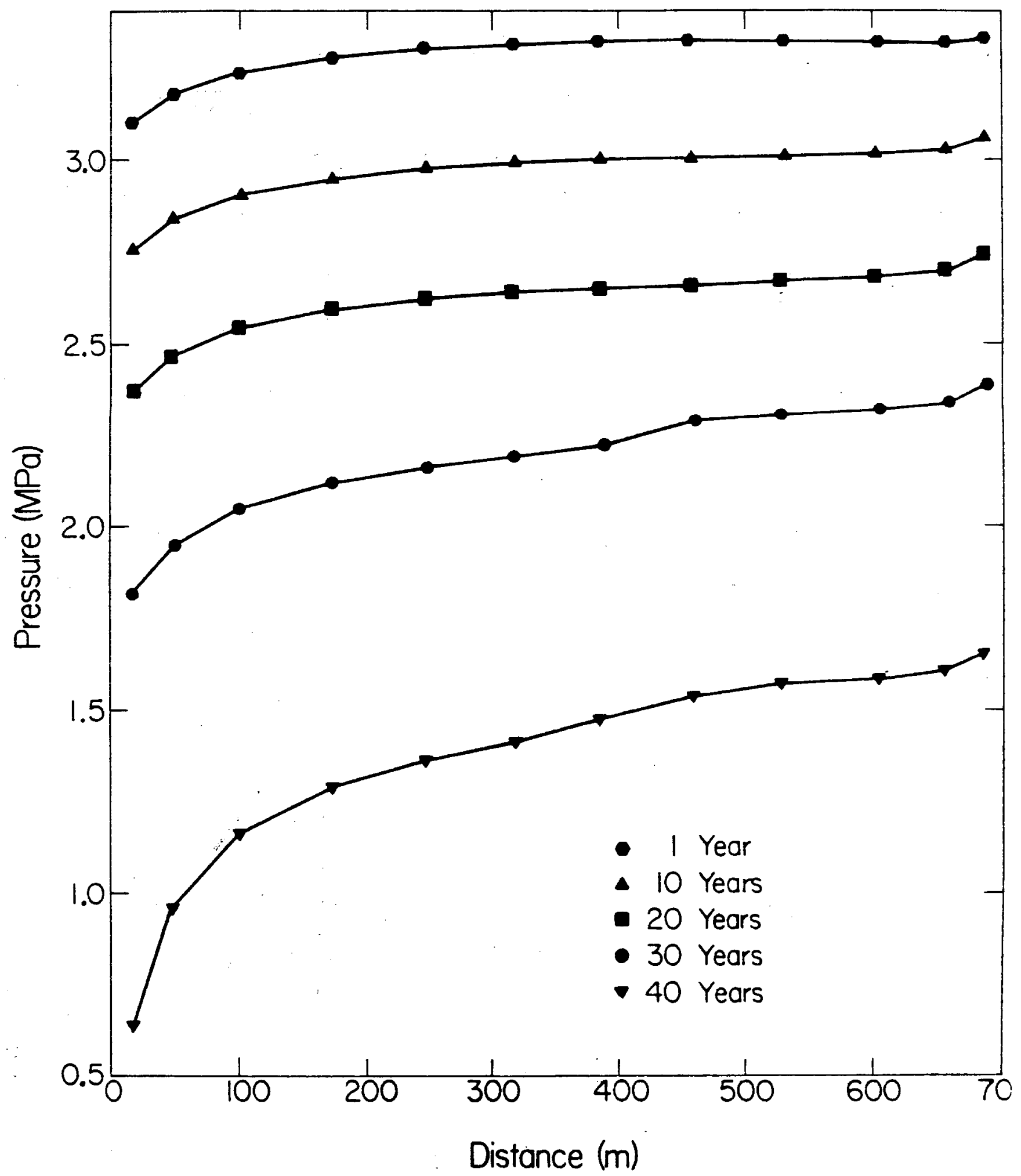

Figure 11a. Pressure profiles along a line joining the production and injection wells for the five-spot problem injection rate $0.025 \mathrm{~kg} / \mathrm{sec}$ ( $100 \%$ of production). 


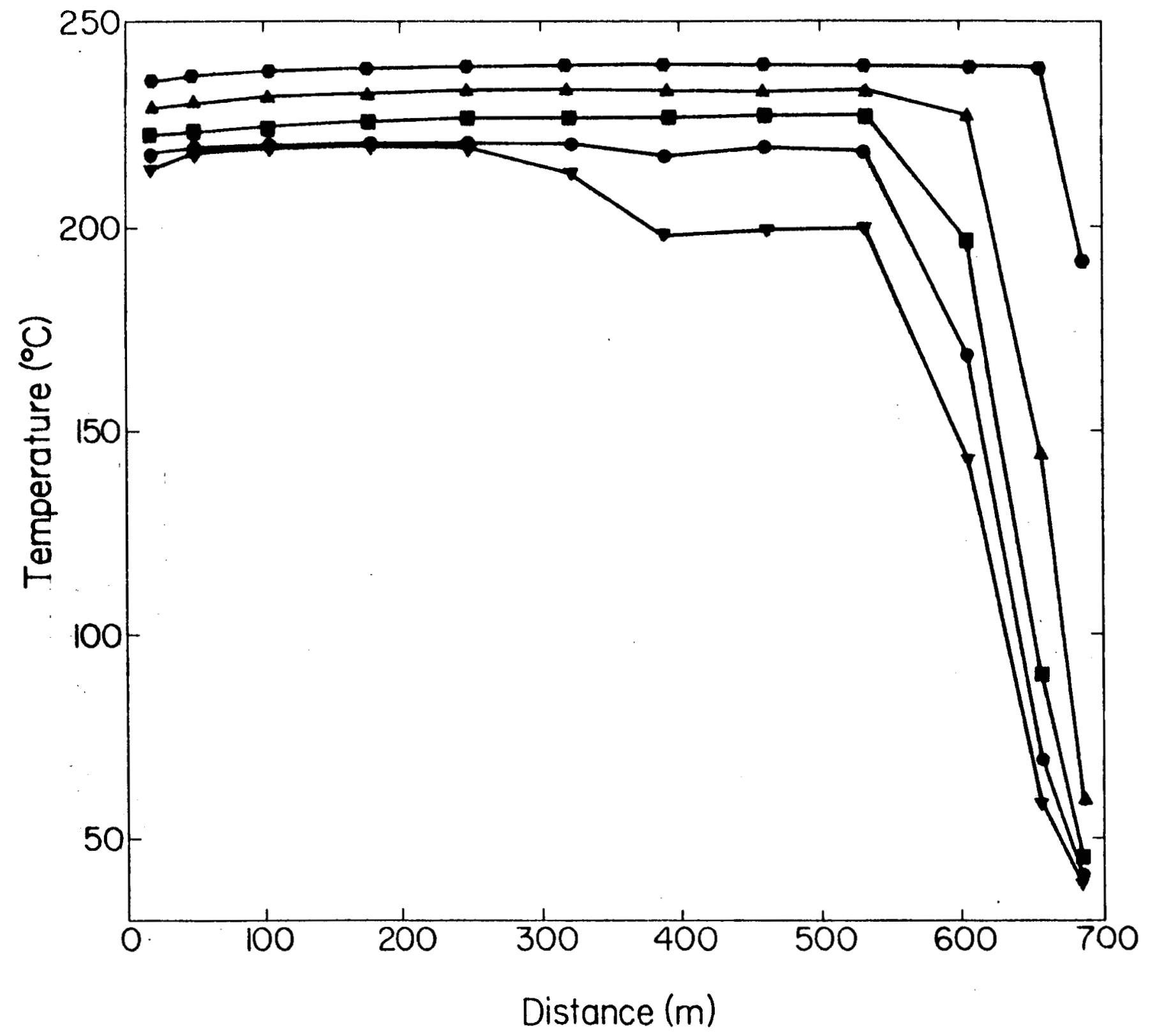

Figure 11b. Temperature proftles along a line foining the production and injection wells for the five-spot problem. Injection rate $0.025 \mathrm{~kg} / \mathrm{sec}(100 \%$ of production). 


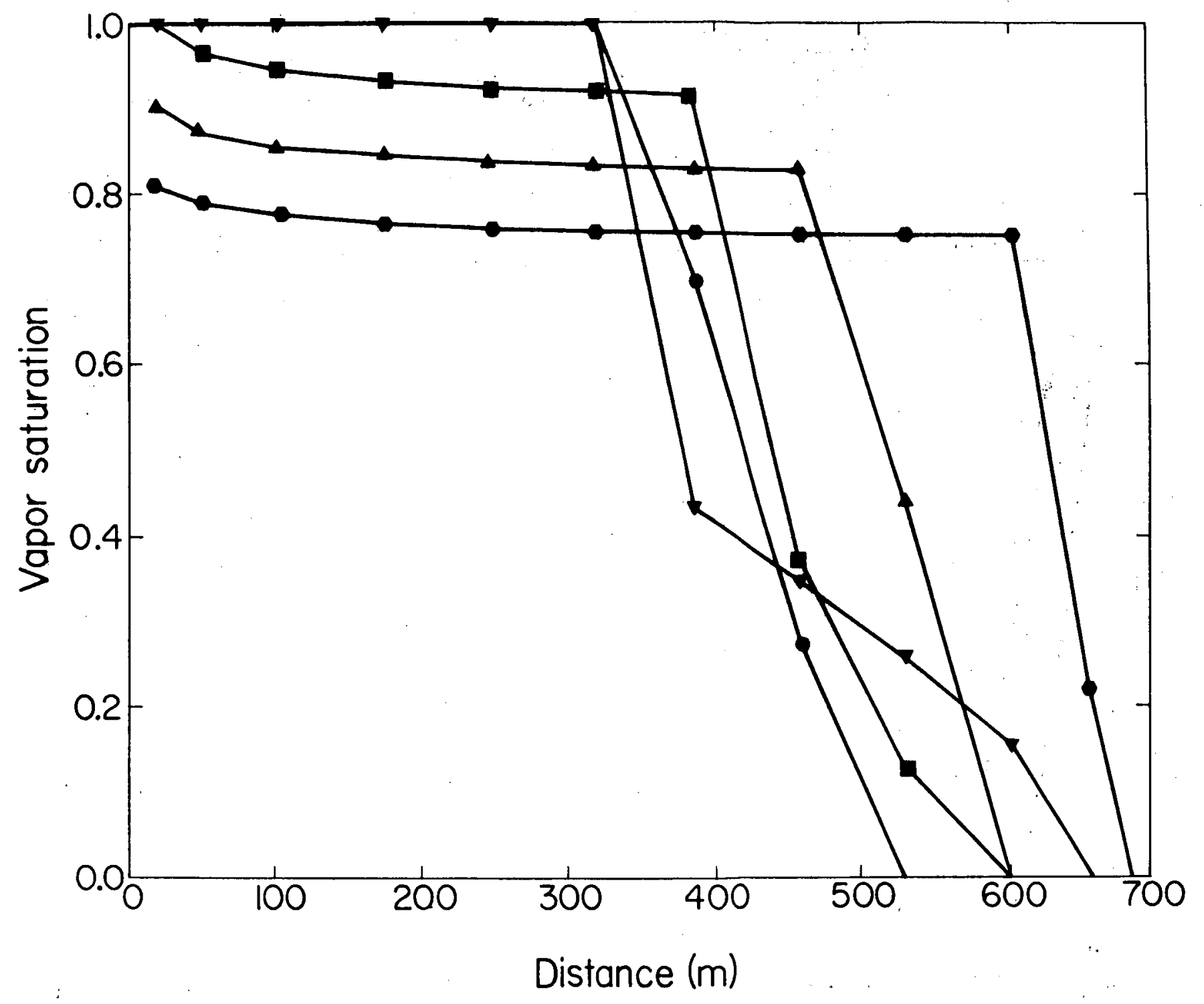

Figure 11c. Vapor saturation profles along a line jolning the production and injection wells for the five-spot problem. Injection rate $0.025 \mathrm{~kg} / \mathrm{sec}(100 \%$ of production). 


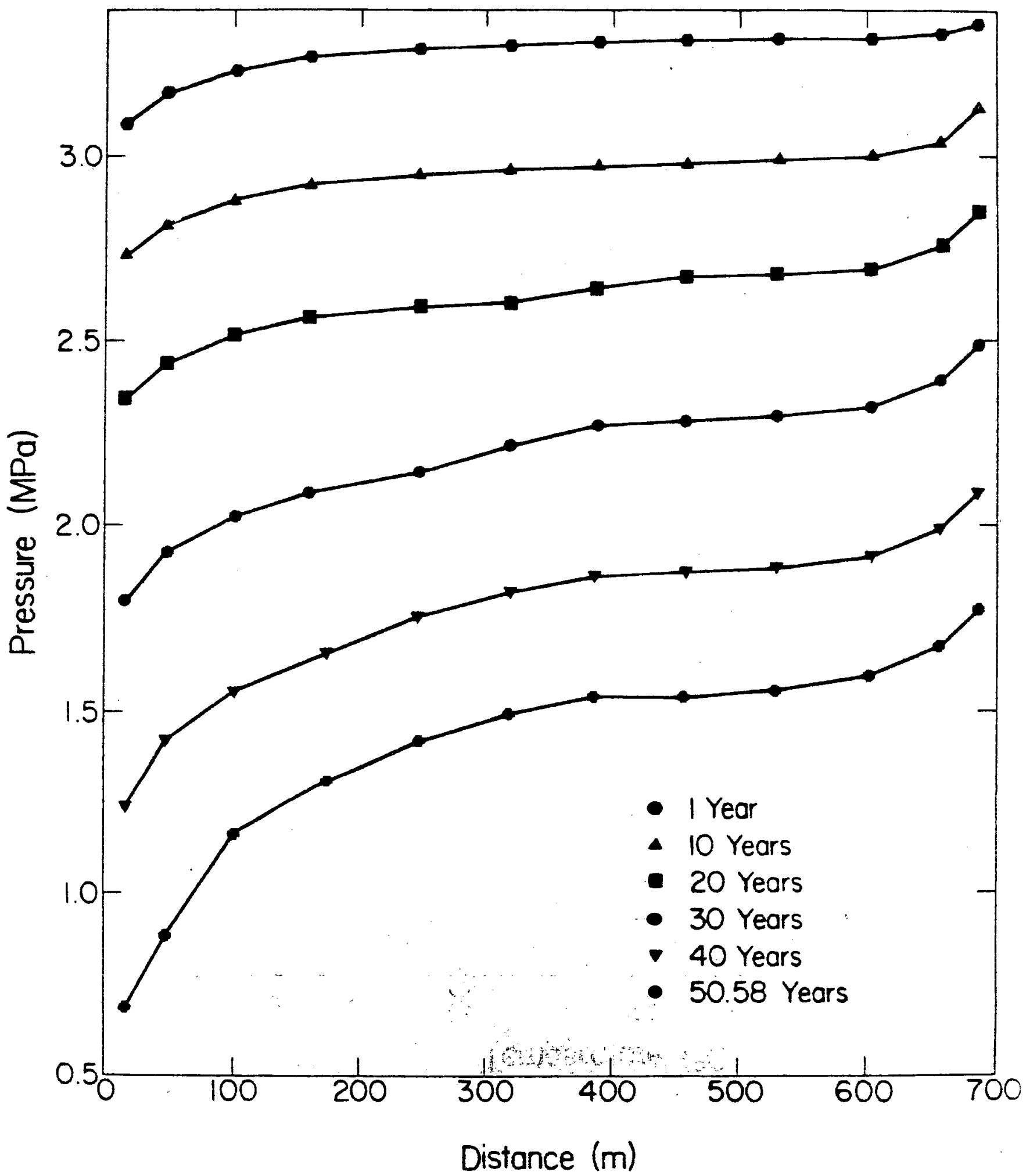

Figure 12a. Pressure profiles along a line joining the production and injectin wells for the five-spot problem. Injection rate $0.05 \mathrm{~kg} / \mathrm{sec}$ (200\% of production). 


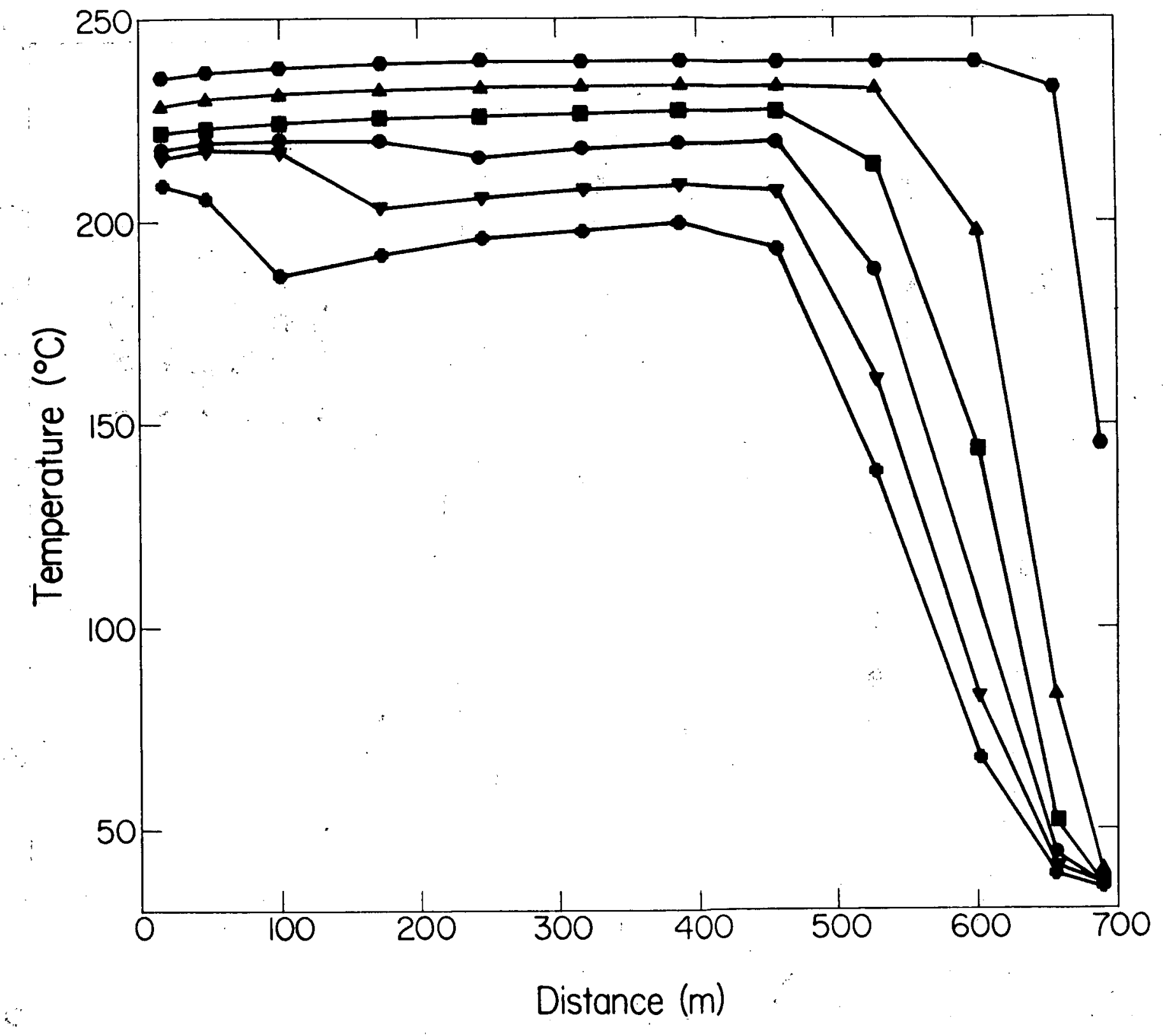

Figure 12b. Temperature profiles along a line joining the production and injection wells for the five-spot problem. Injection rate $0.05 \mathrm{~kg} / \mathrm{sec}(200 \%$ of production). 


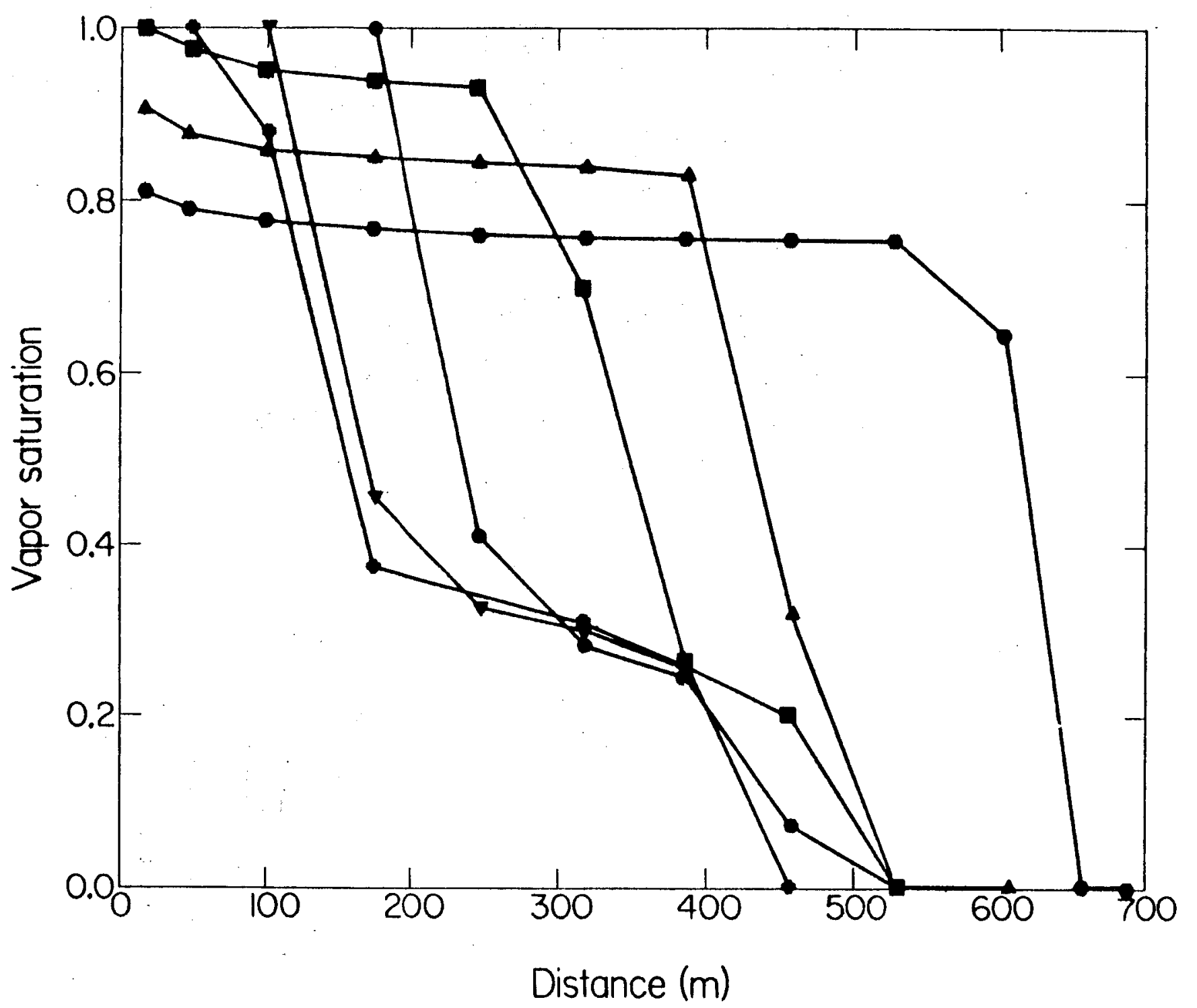

Figure 12c. Vapor saturation profiles along a line jointing the production and infection wells for the five-spot problem. Injection rate $0.05 \mathrm{~kg} / \mathrm{sec}(200 \%$ of production). 


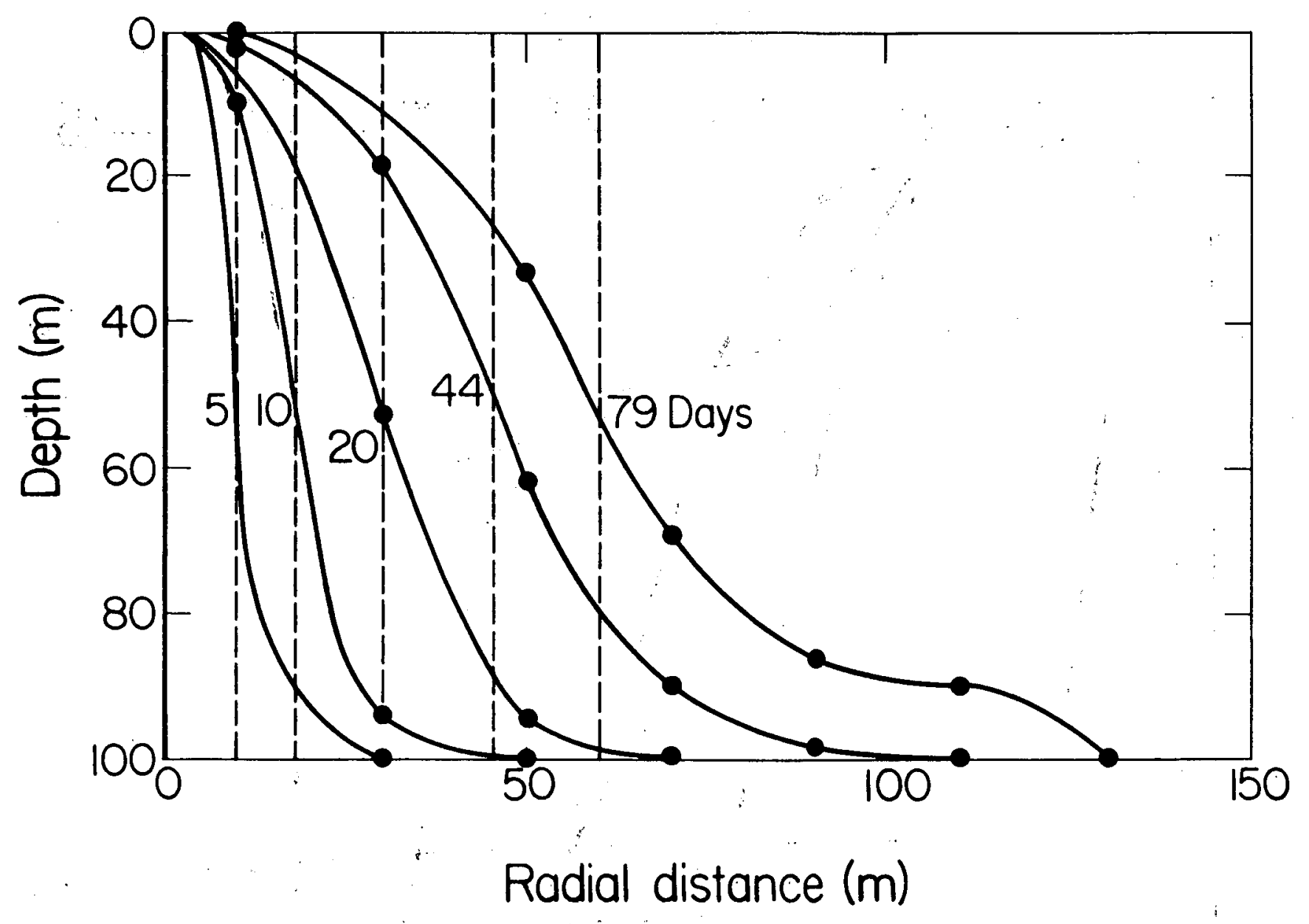

F1gure 13. Locations of the hydrodynamic front for injection into. a thick reservoir. Case 1, no gravity, ---;

Case 2, gravity, 


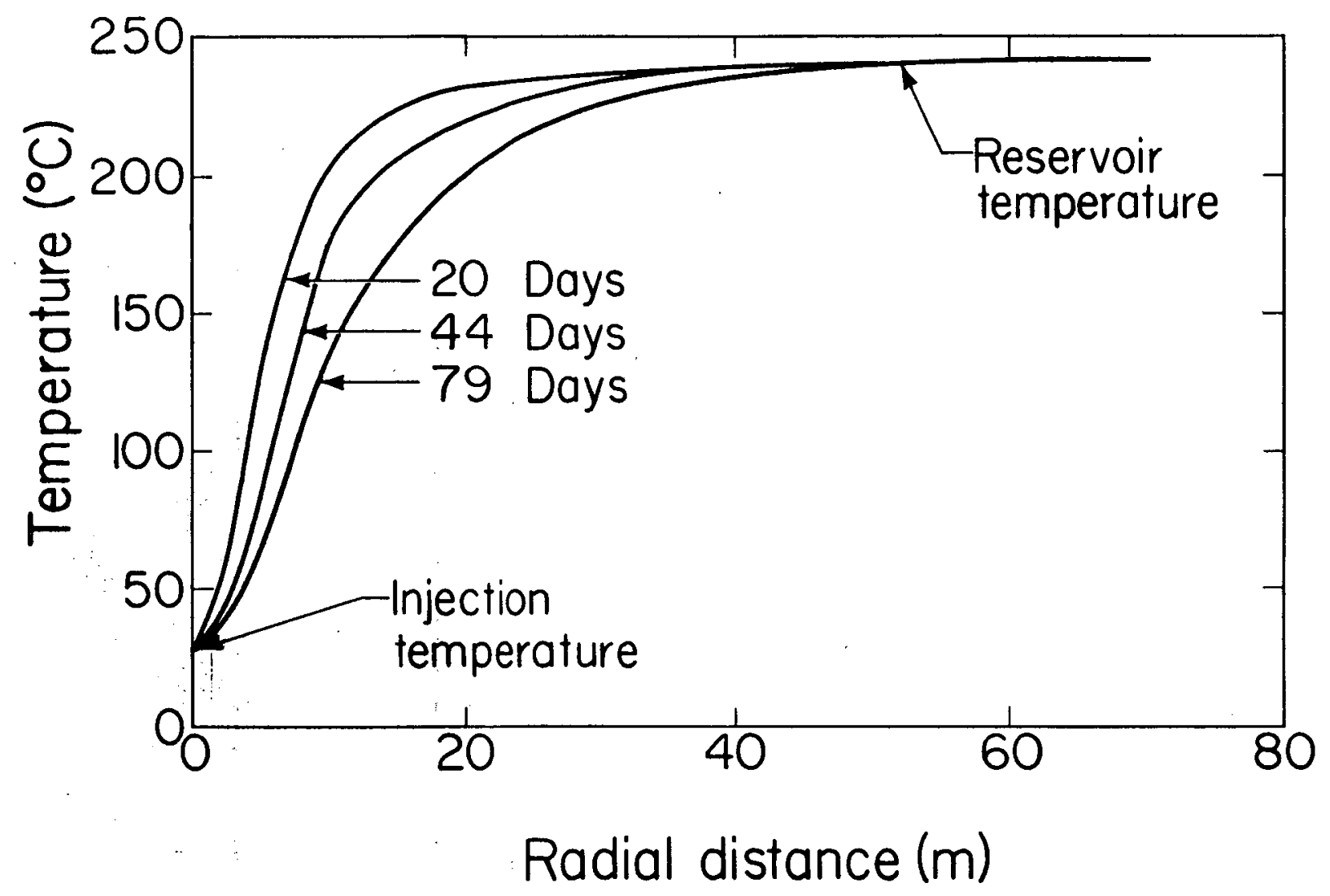

Figure 14. Temperature profiles for injection into a thick reservoir (case 1) along a line in the horizontal central plane (50 m depth). 


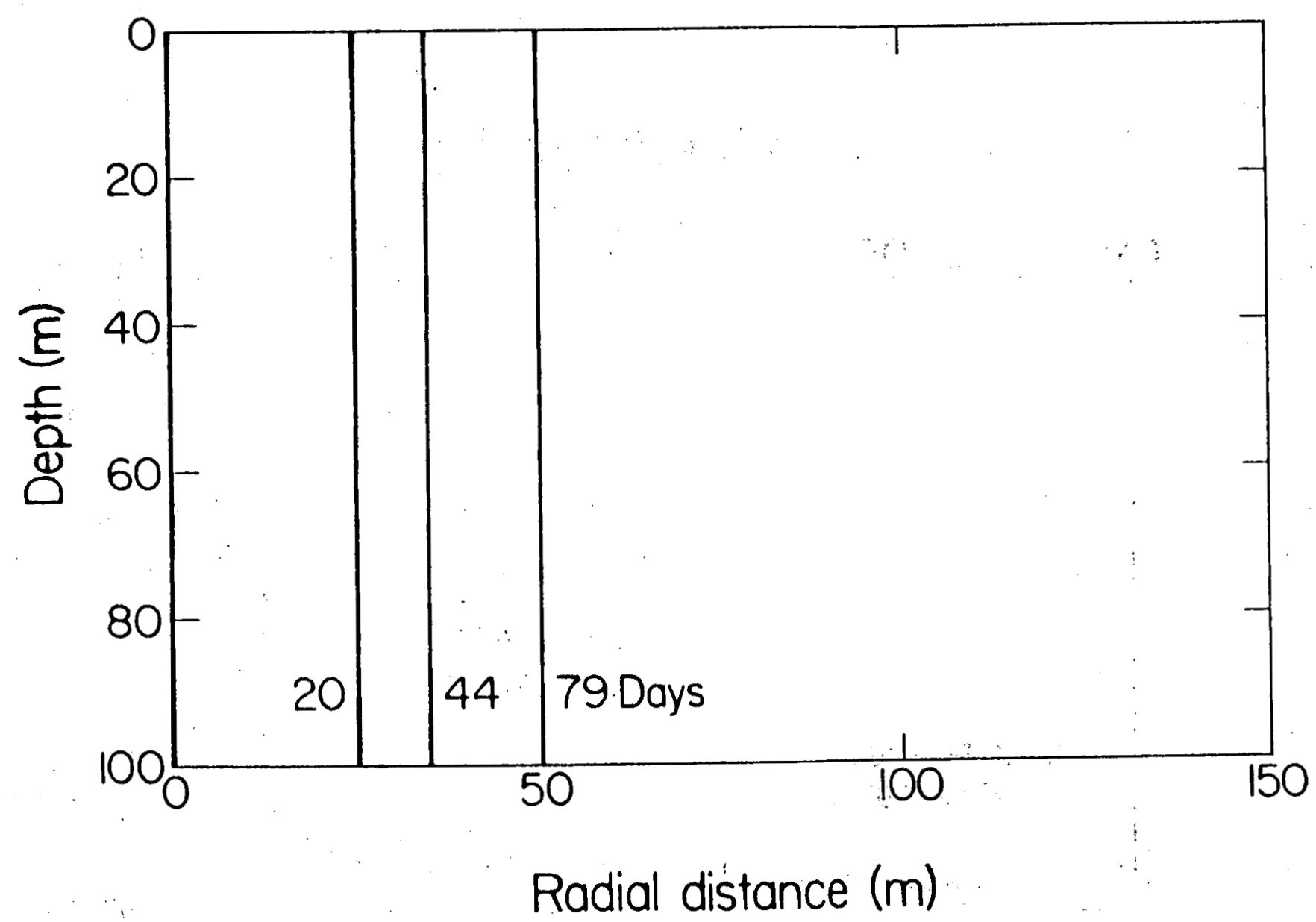

Figure 15. Locations of the thermal front for injection into a thick reservoir (rase 2). 


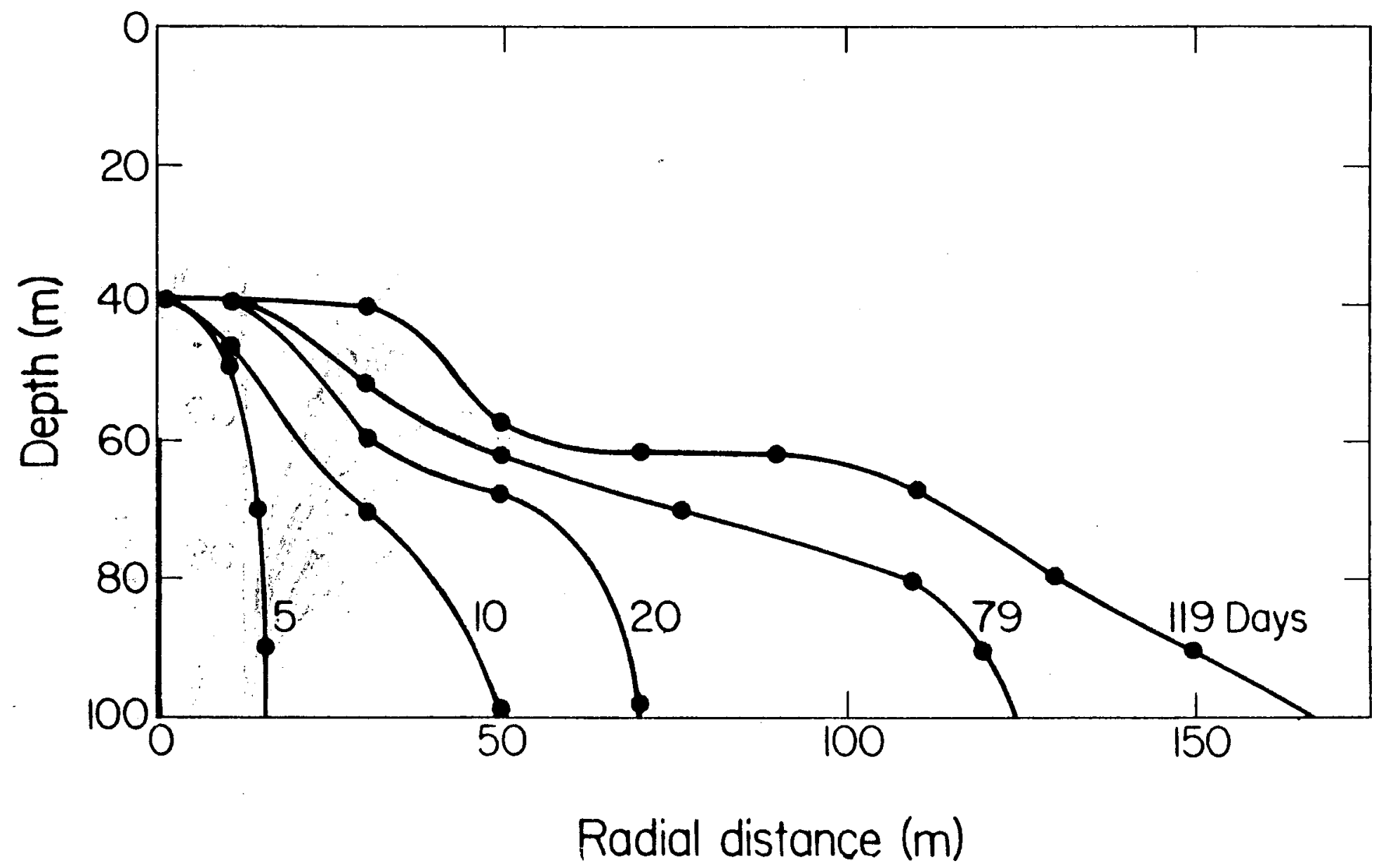

Figure 16. Locations of the hydrodynamic front for injection into a thick reservoir. Case 5, bottom injection at $15 \mathrm{~kg} / \mathrm{sec}$. 


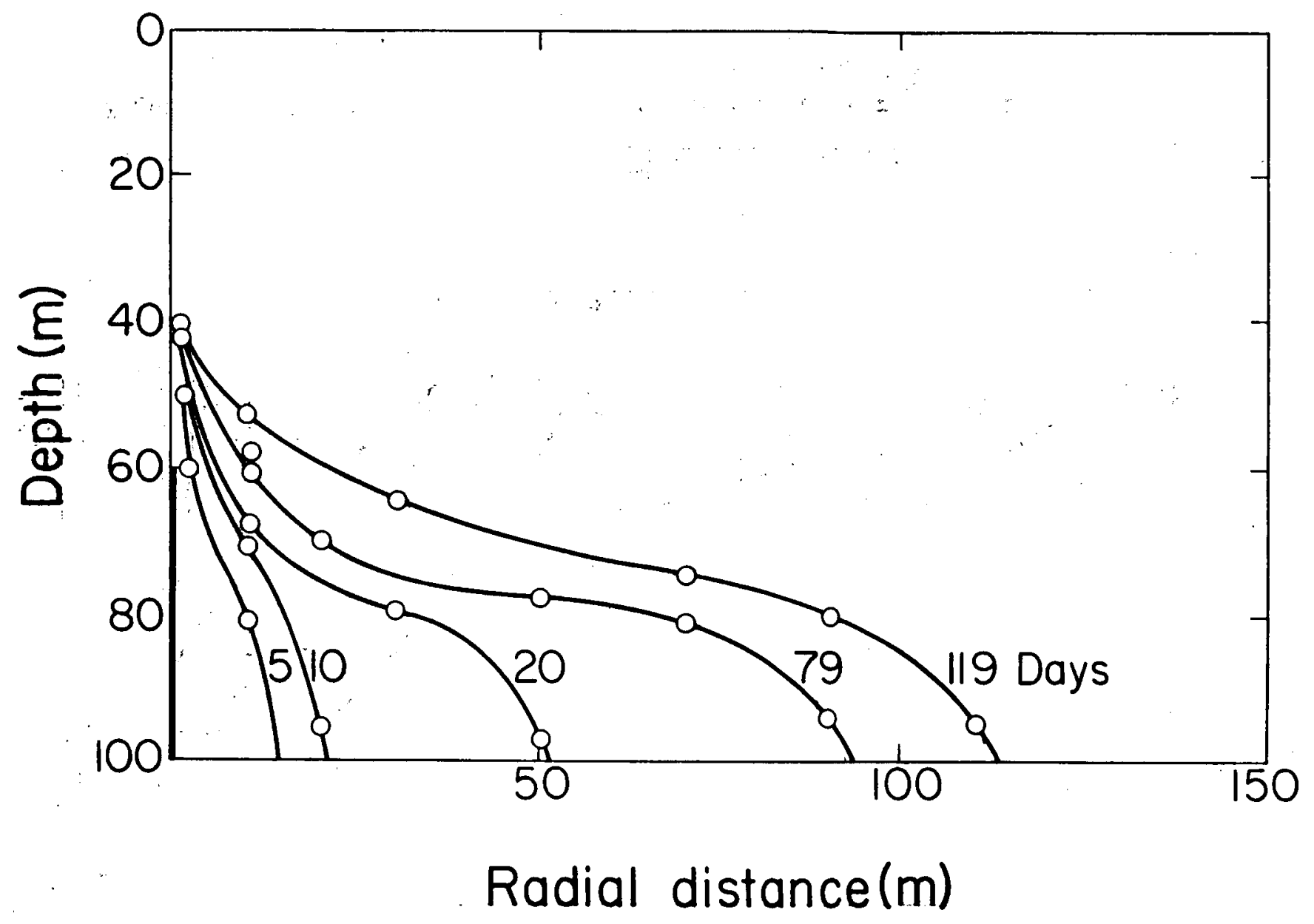

Figure 17. Locations of the hydrodynamic front for injection into a thick reservoir. Case 6 , bottom injection at $6 \mathrm{~kg} / \mathrm{sec}$. 


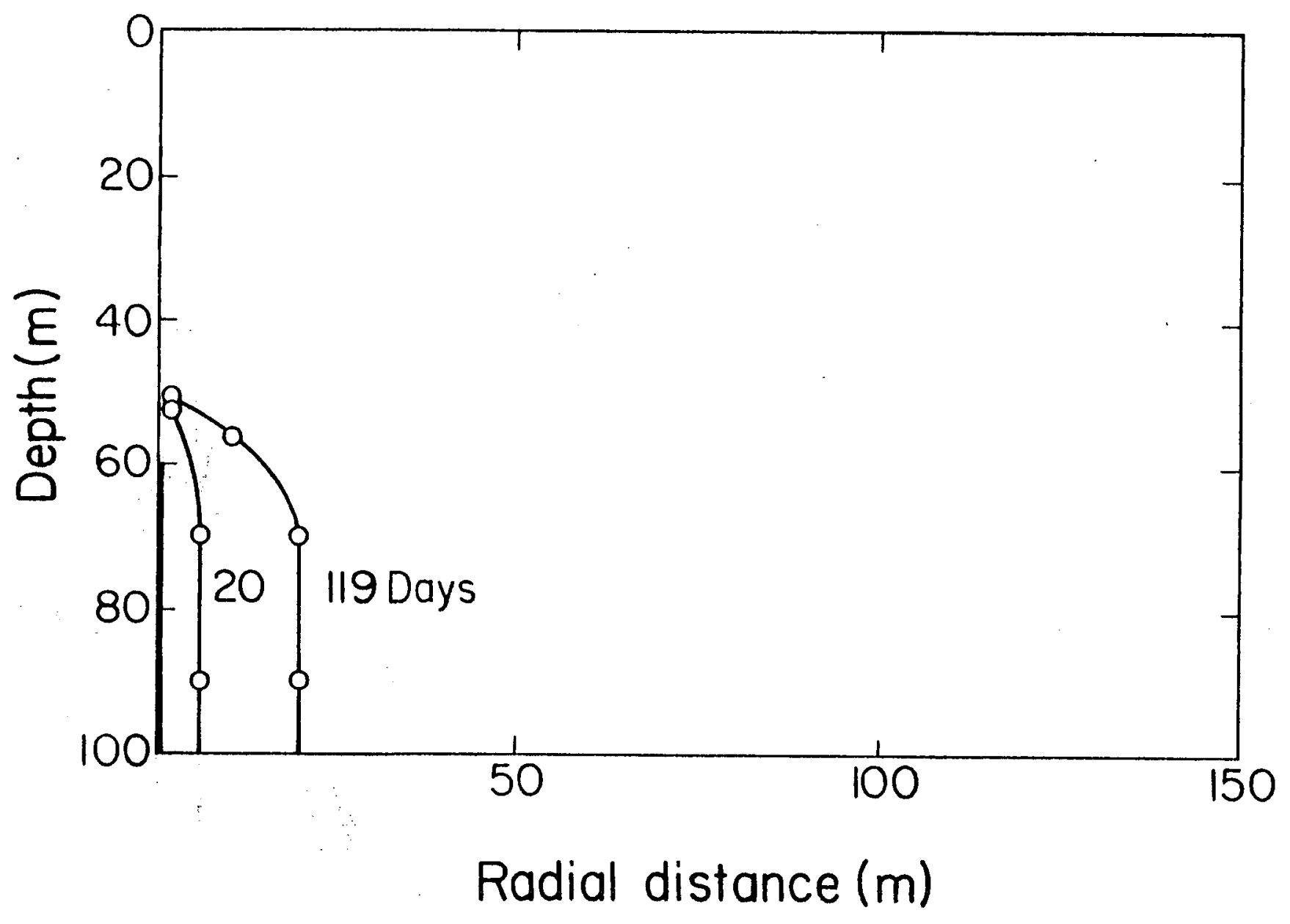

Figure 18. Locations of the thermal front for injection into

a thick reservolr. Case 5 , bottom injection at $15 \mathrm{~kg} / \mathrm{sec}$. 


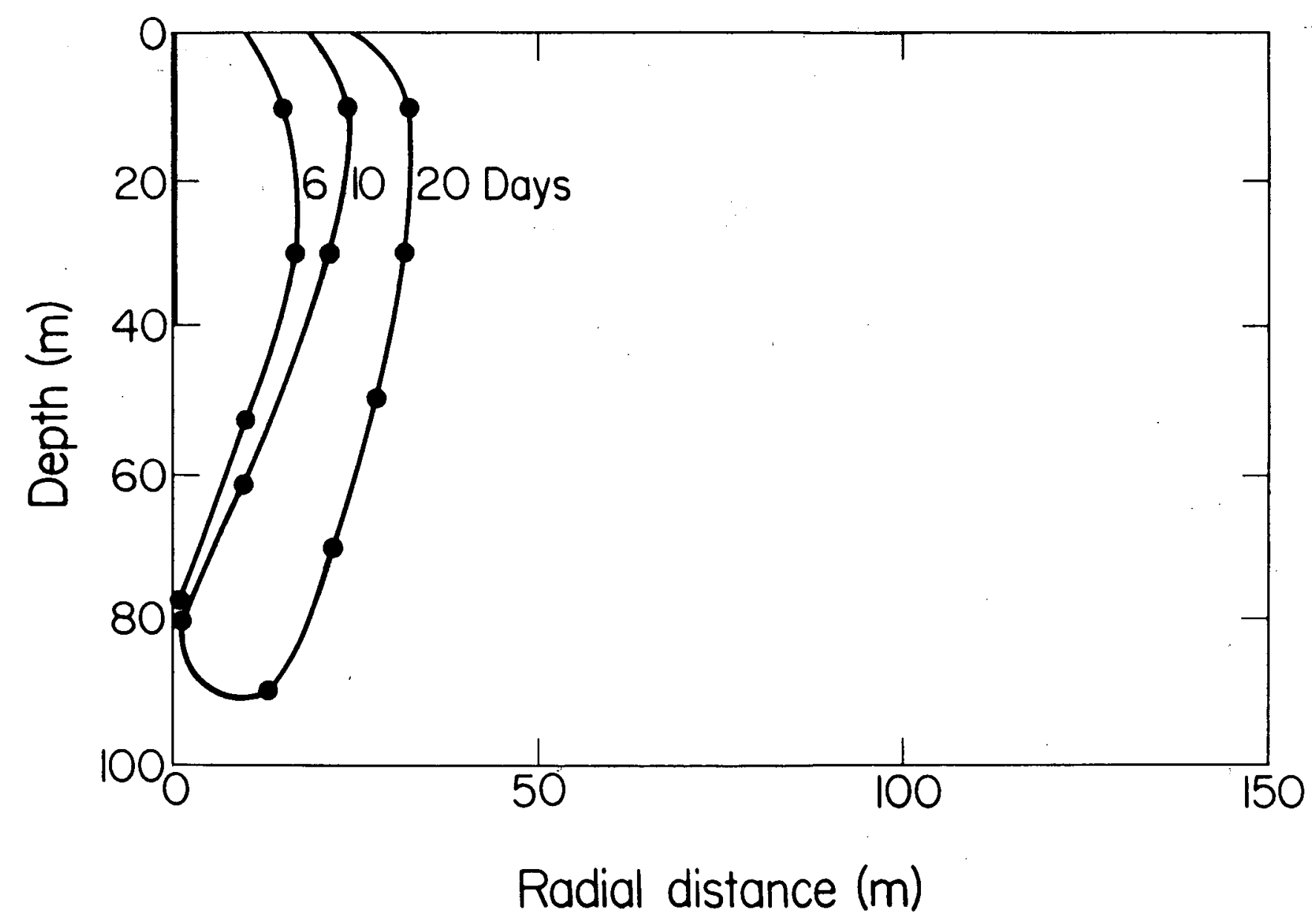

Figure 19. Locations of the hydrodynamic front for injection into a thick reservoir. Case 3, top injection at $15 \mathrm{~kg} / \mathrm{sec}$. 


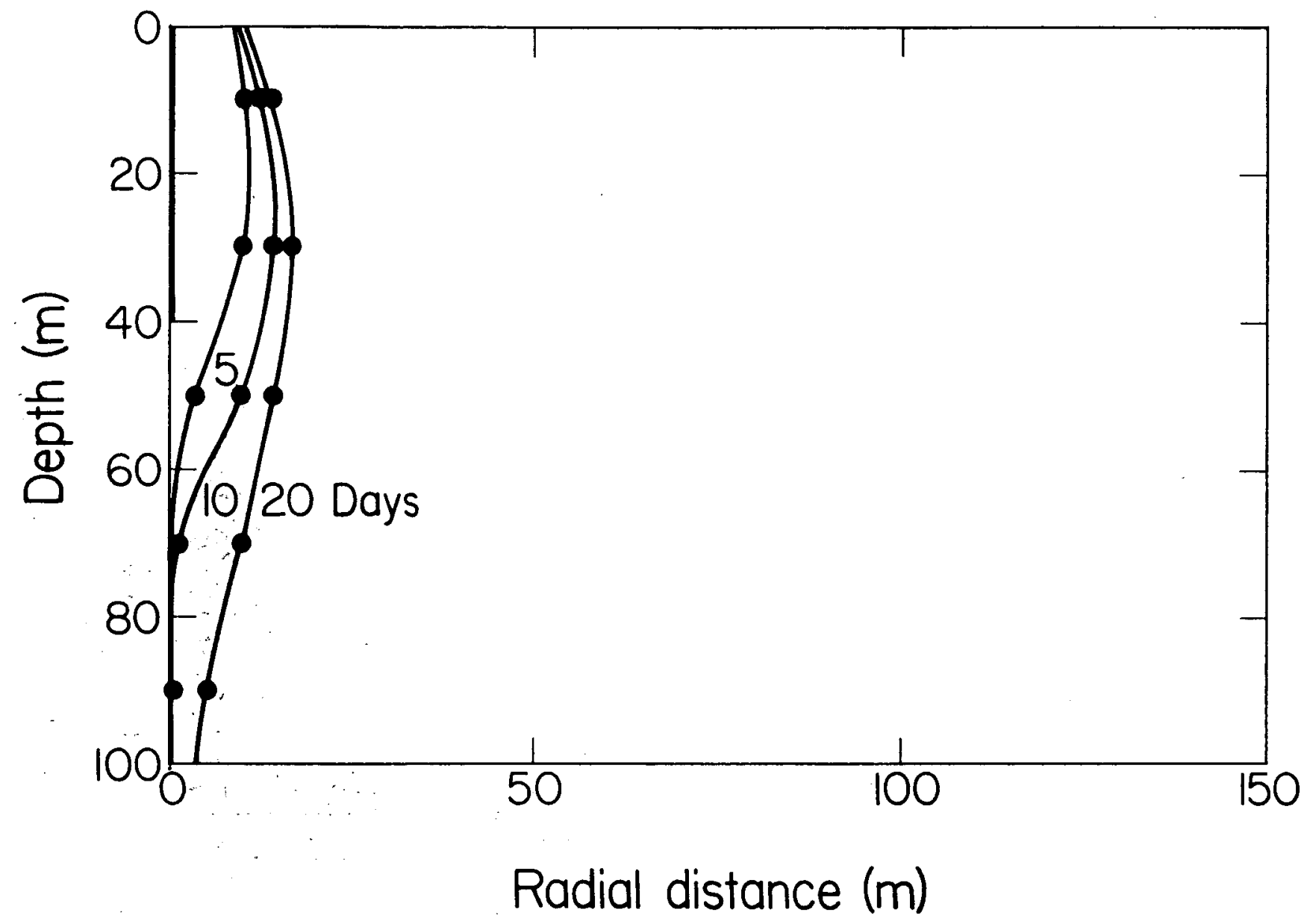

Figure 20. Locations of the hydrodynamic front for injection into a thick reservoir. Case 4 , top injection of
$6 \mathrm{~kg} / \mathrm{sec}$. 


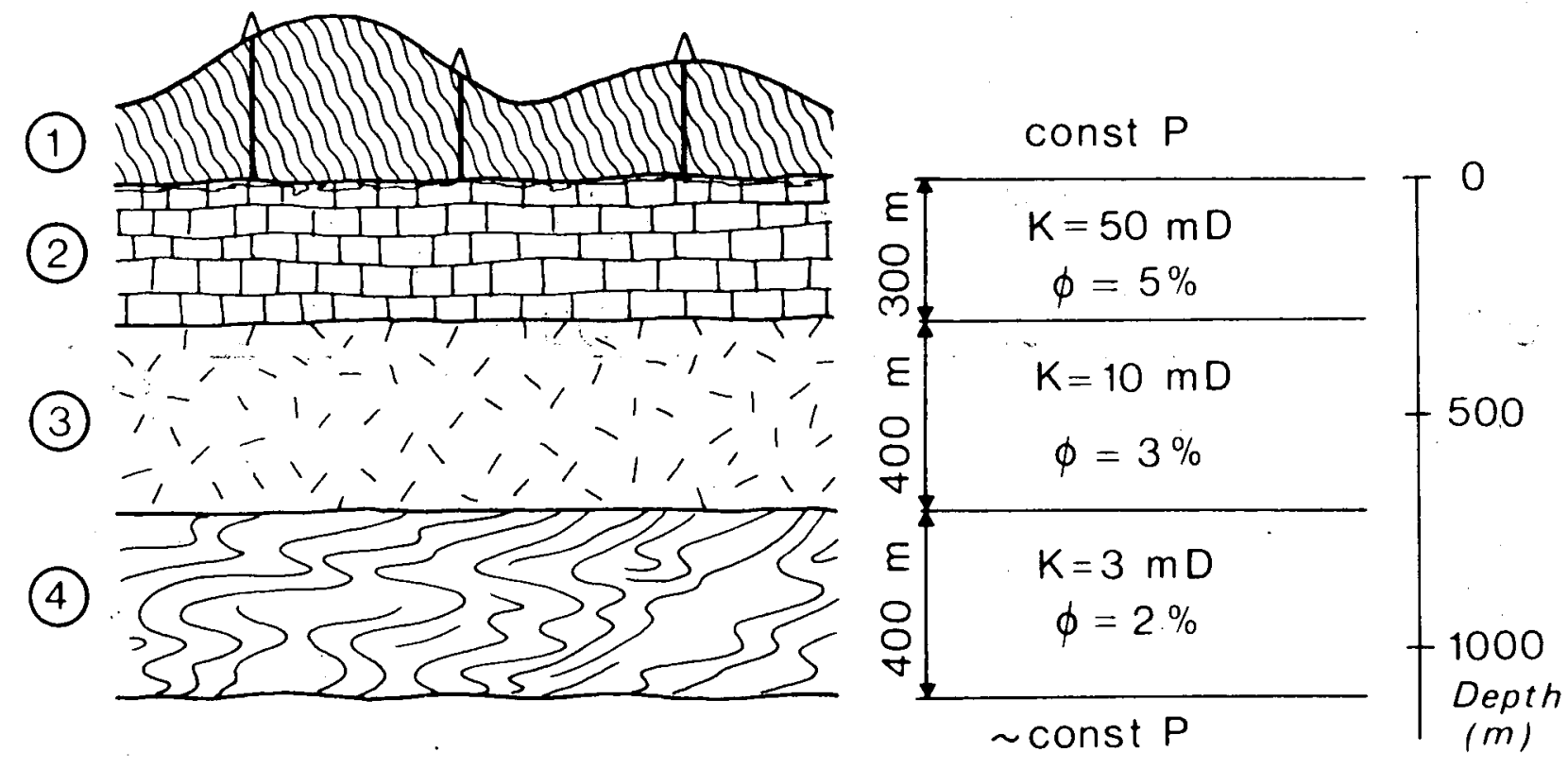

XBL $8012-12874$

Figure 21. Linear flow model for reinjection studies. Rock and thermodynamic characteristics are similar to those existing in some zones of Larderello: 1 - caprock, 2 - Carbonate formations, 3 - fractured quartzites and phyllites, and 4 - phyllites. 

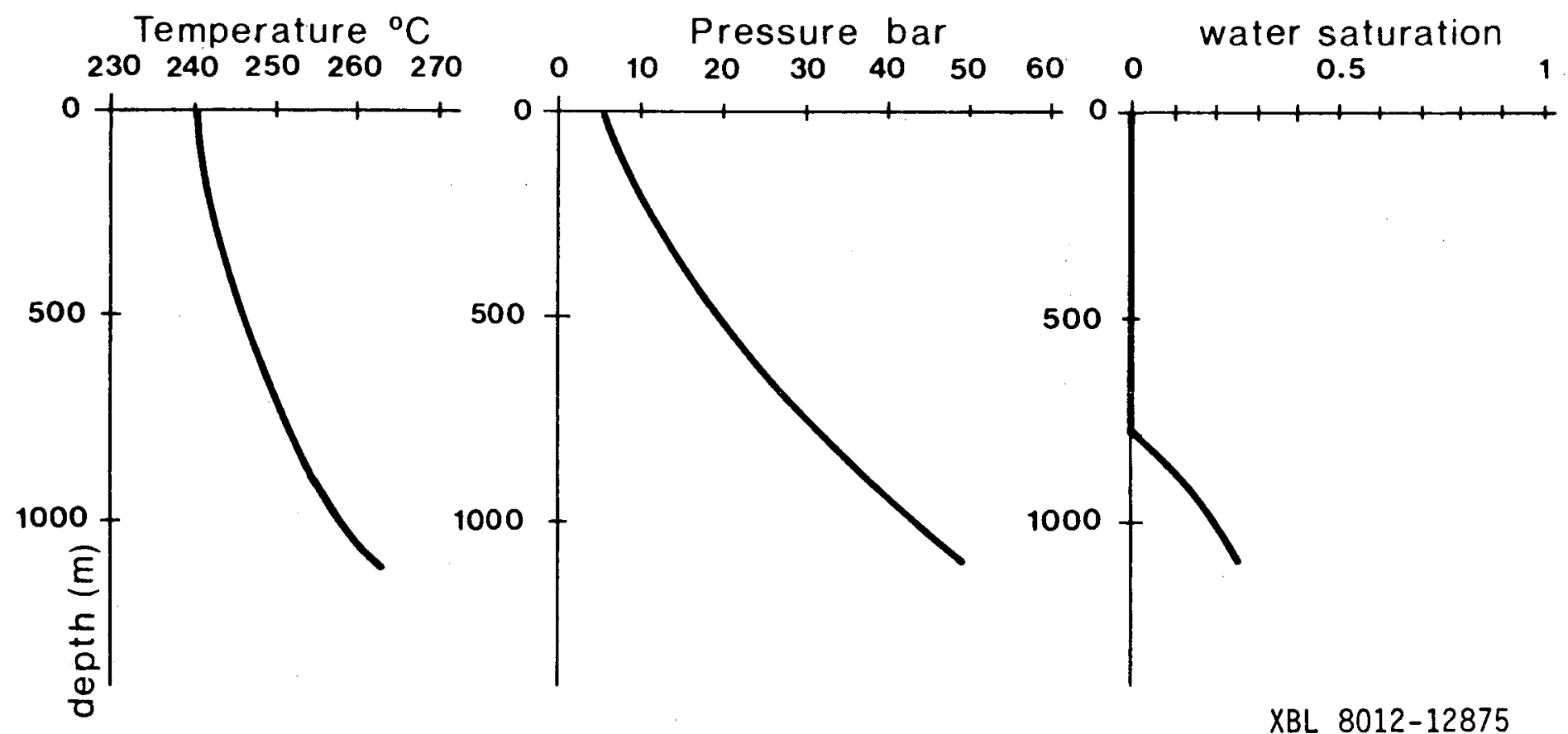

Figure 22. Initial conditions for the model of Figure 21 .

XBL 8012-12875 


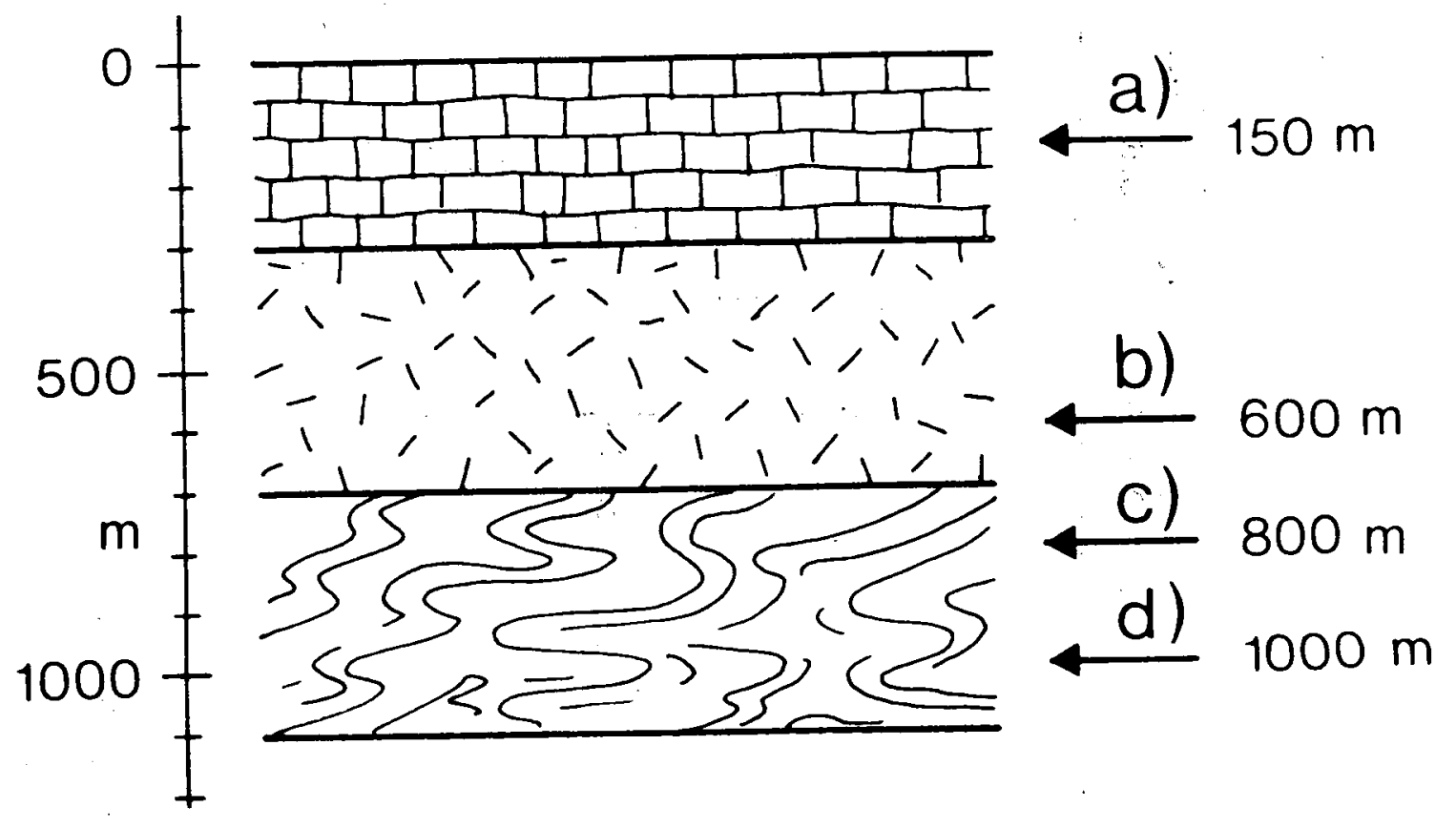

XBL 8012-12872

Figure 23. Depths of injection for cases a), b), c), d). 


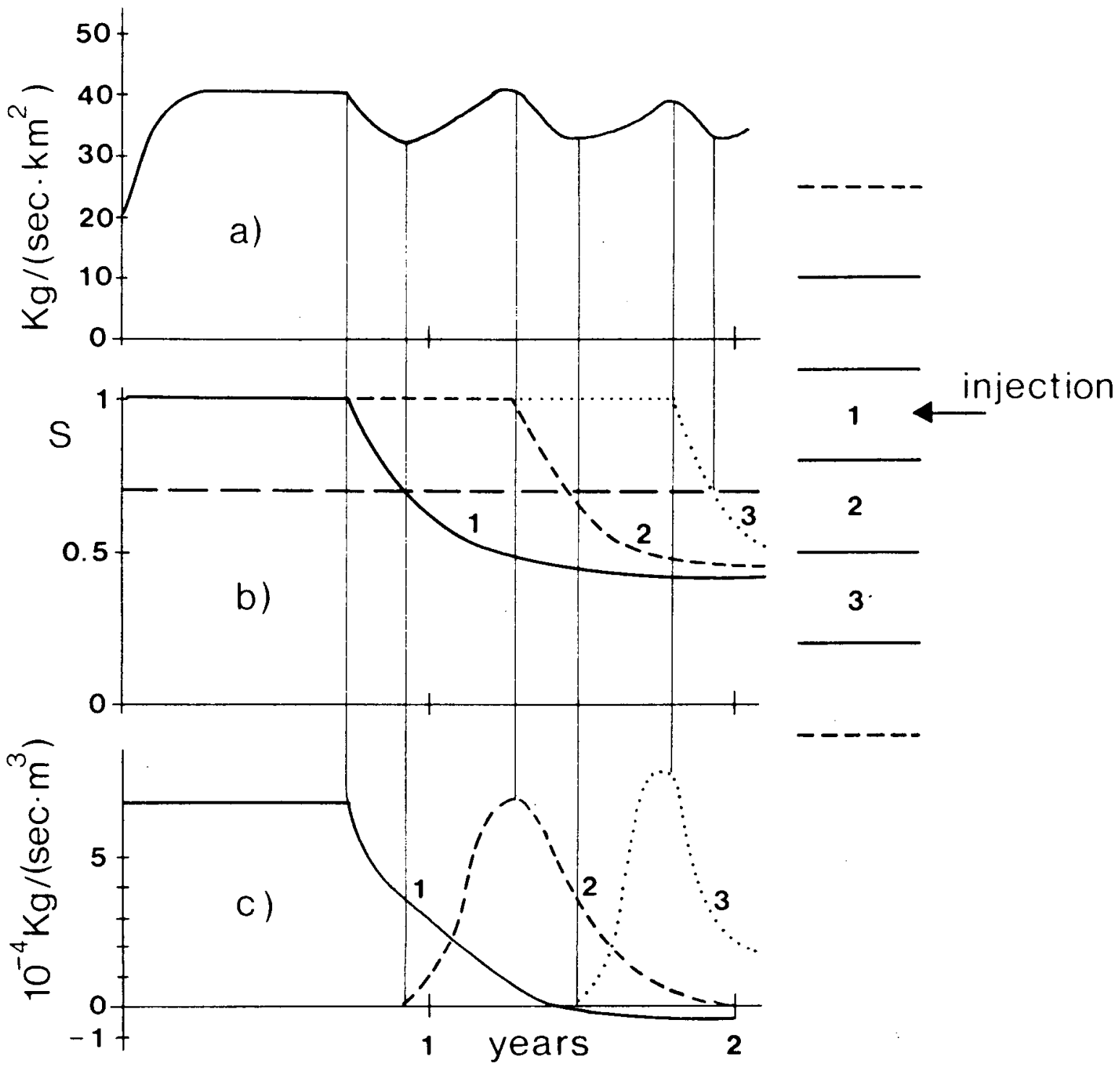

XBL $8012-12877$

Figure 24. Discretization effects in simulations of the injection of cold water in superheated steam zones of the reservoir. a) production rate, b) steam saturation (immobile water saturation is 0.7 ), and c) boiling rate. 


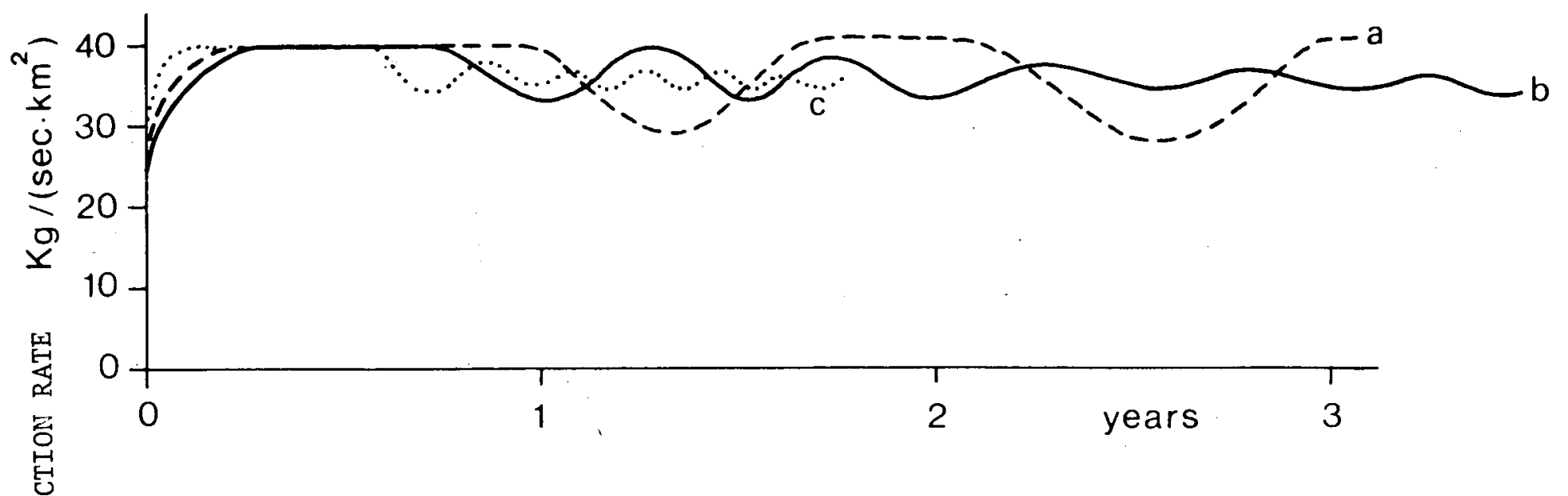

XBL 8012-12876

Figure 25. Results of simulations with different sizes of the grid elements in the linear flow model. a) $\Delta z=6.66 \mathrm{~m}, \mathrm{~b}) \Delta \mathrm{z}=3 \mathrm{~m}$, and

c) $\Delta \mathrm{Z}=1 \mathrm{~m}$. 

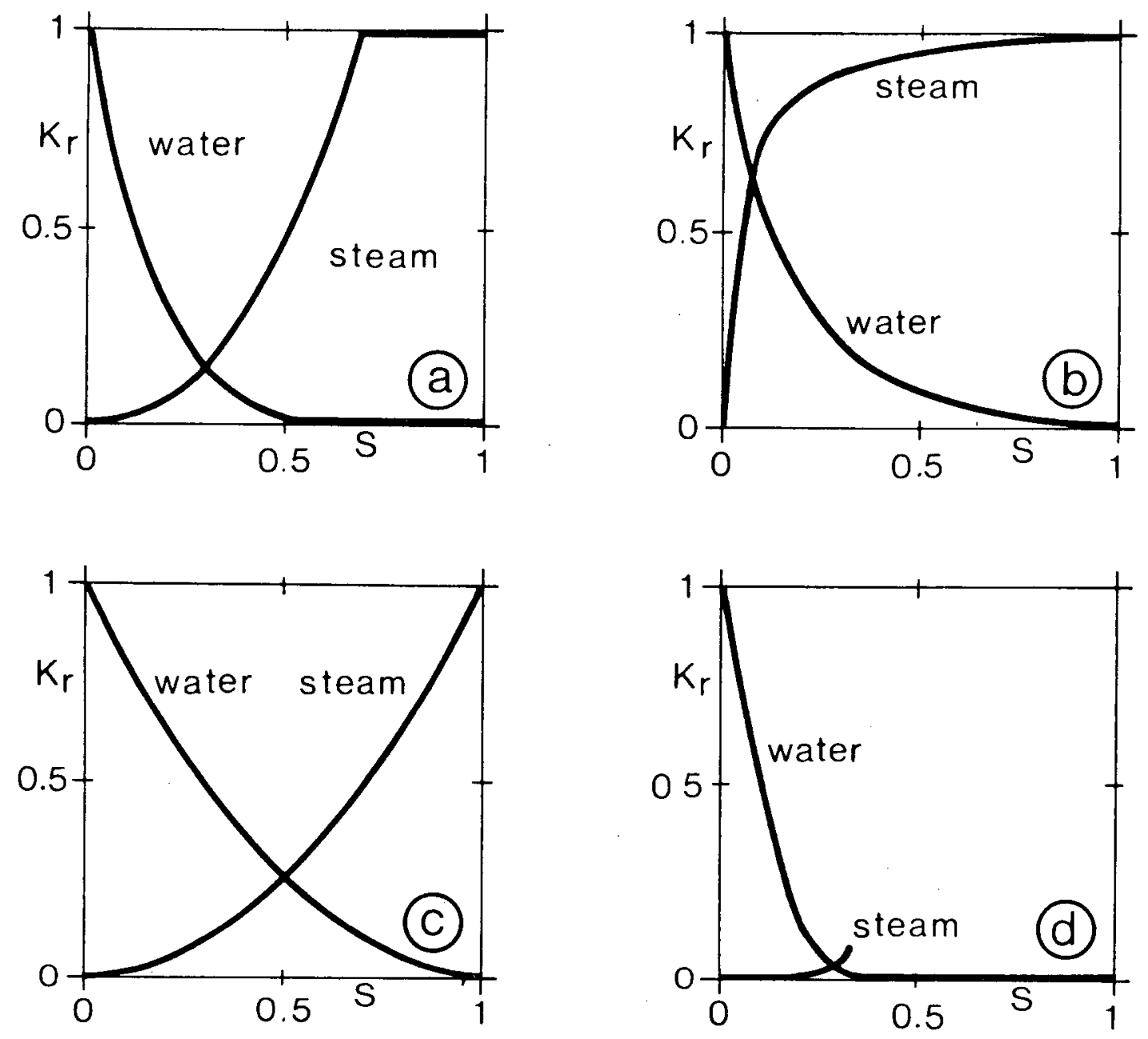

XBL $8012-12871$

Figure 26. Examples of relative permeability curves for water and steam. 


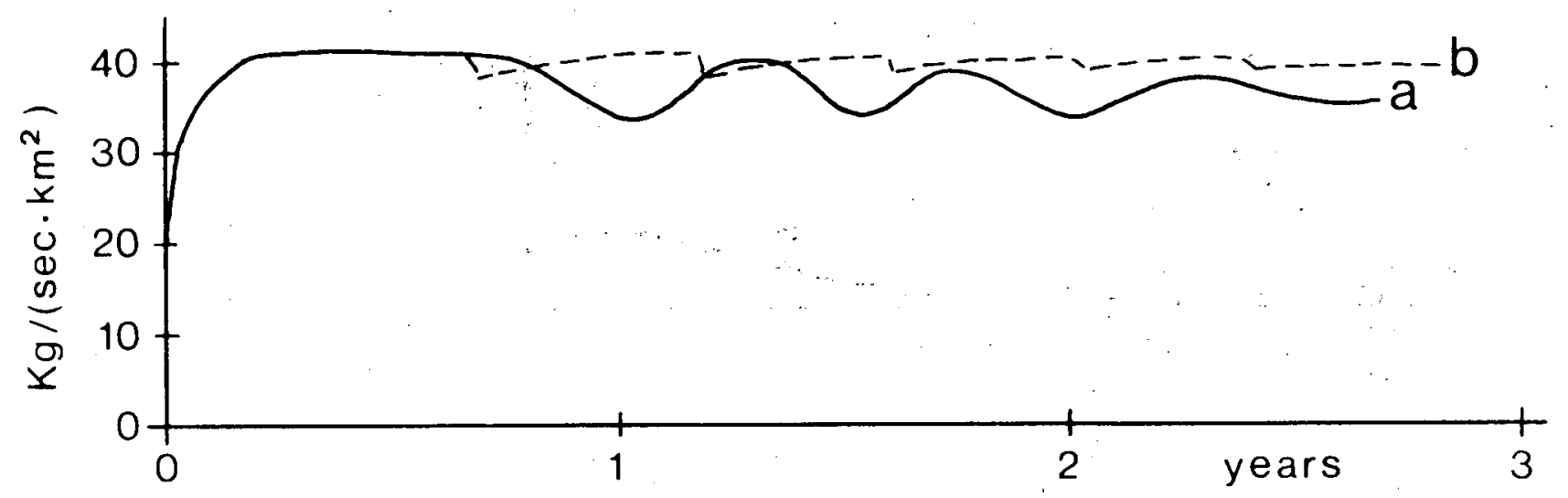

XBL $8012-12873$

Figure 27. Results of simulation with different relative permeabilities. a) Corey's equation $\mathrm{Swc}=.3, \mathrm{Sgc}=0$ (Figure 26a), b) Relative permeability from Wairakei production data (Figure 26b). 


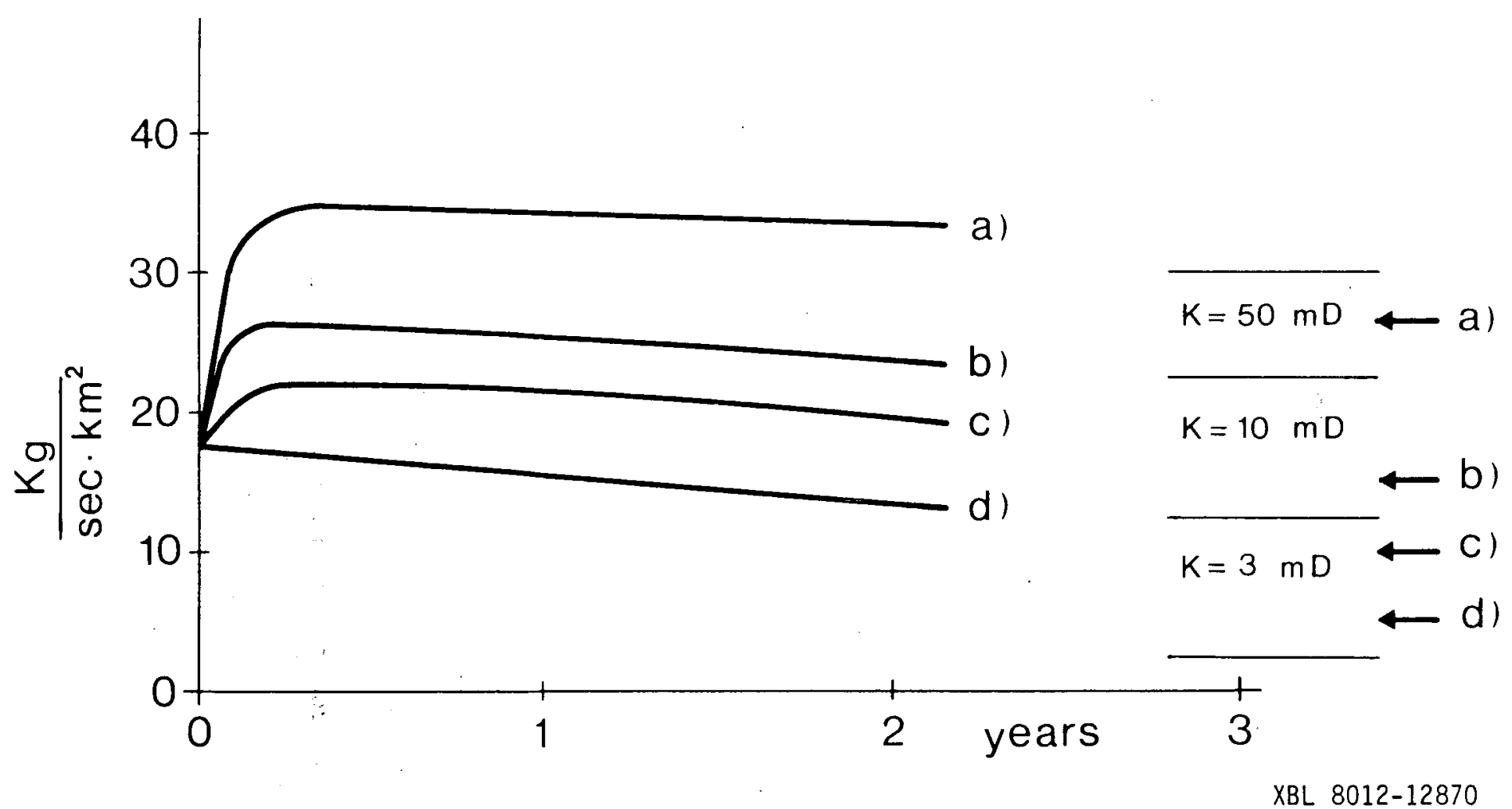

Figure 28. Effect of injection at different depths in the linear flow model (smoothed curves). 


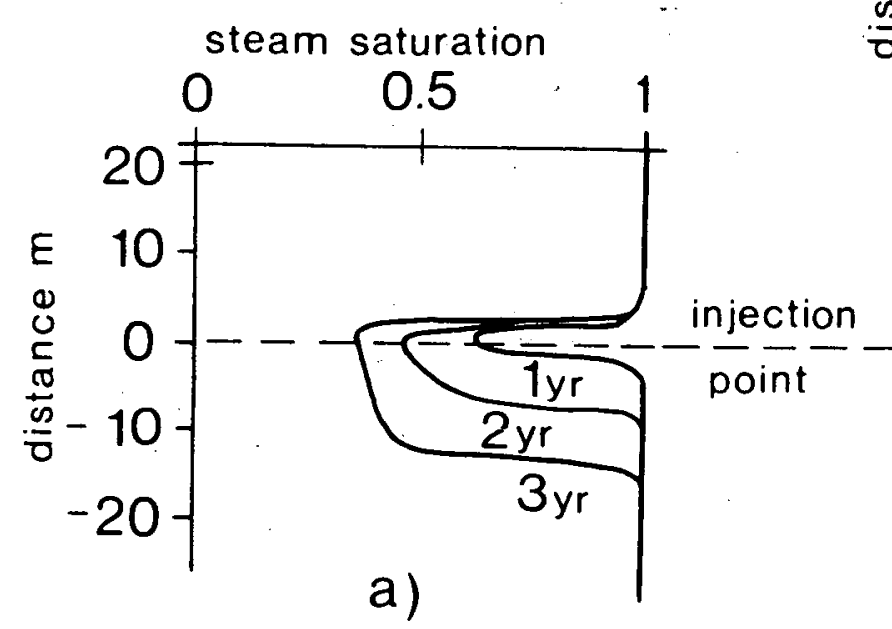

a)

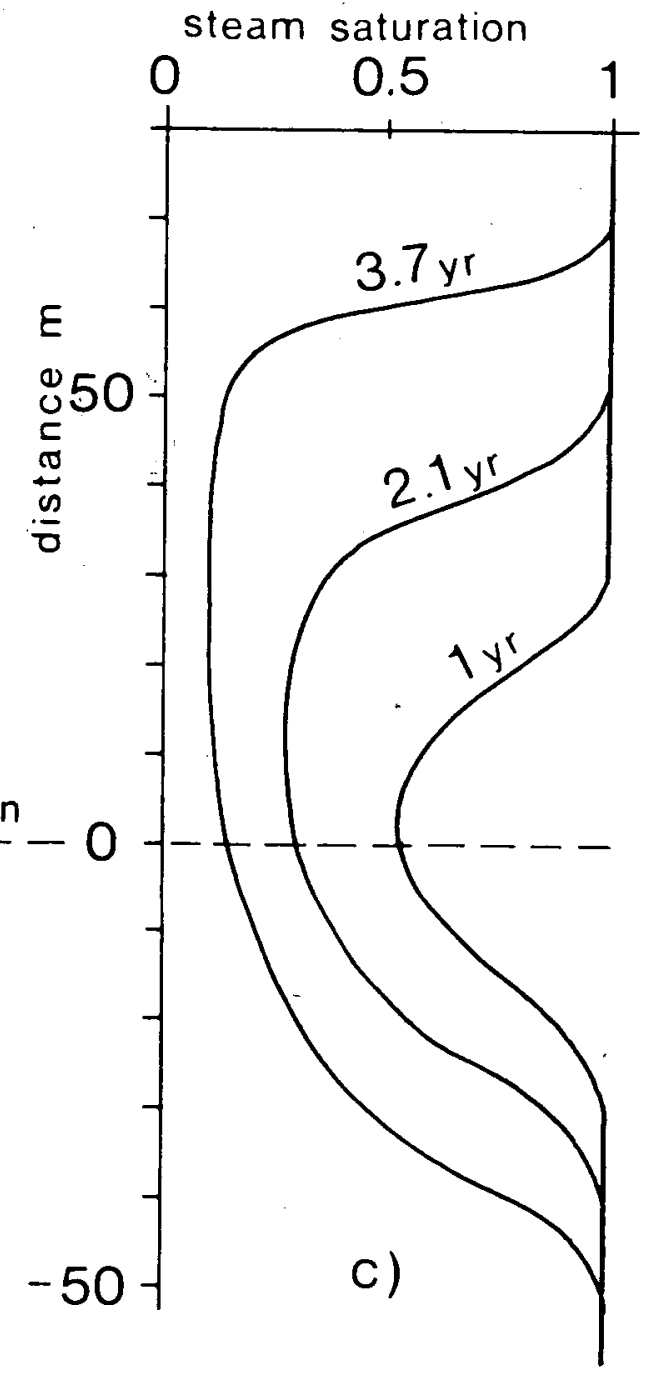

XBL $8012-12878$

Figure 29. Saturation around the injection point in cases a) and c) of Figure 23. 